\title{
ZnO micro/nanocrystals grown by Laser Assisted Flow Deposition
}

\author{
J. Rodrigues ${ }^{1}$, A. J. S. Fernandes ${ }^{1}$, D. Mata ${ }^{1,2}$, T. Holz ${ }^{1,2}$, R. G. Carvalho ${ }^{1,2}$, R. Fath Allah ${ }^{3}$, T. Ben ${ }^{3}$, \\ D. Gonzalez ${ }^{3}$, R. F. Silva ${ }^{2}$, A. F. da Cunha ${ }^{1}$, M. R. Correia ${ }^{1}$, L. C. Alves ${ }^{4}$, K. Lorenz ${ }^{4}$, A. J. Neves ${ }^{1}$, \\ F. M. Costa $^{1}$, T. Monteiro \\ ${ }^{1}$ Departamento de Física \& I3N, Universidade de Aveiro, Campus Universitário de Santiago, 3810- \\ 193 Aveiro, Portugal \\ ${ }^{2}$ CICECO, Departamento de Engenharia de Materiais e Cerâmica, Universidade de Aveiro, Campus \\ Universitário de Santiago, 3810-193 Aveiro, Portugal \\ ${ }^{3}$ Departamento de Ciencia de los Materiales e I. M. y Q. I, Facultad de Ciencias, Universidad de \\ Cádiz, E-11510 Puerto Real, Spain \\ ${ }^{4}$ IST, Instituto Superior Técnico, Campus Tecnológico e Nuclear, Universidade de Lisboa, EN10, \\ 2695-066 Bobadela LRS, Portugal
}

\begin{abstract}
Laser assisted flow deposition (LAFD) is a very high yield method based on a vapor-solid mechanism, allowing the production of $\mathrm{ZnO}$ crystals in a very short time. The LAFD was used in the growth of different morphologies (nanoparticles, tetrapods and microrods) of $\mathrm{ZnO}$ micro/nanocrystals and their microstructural characterization confirms the excellent crystallinity of the wurtzite structure. The optical properties of the as-grown $\mathrm{ZnO}$ crystals investigated by low temperature photoluminescence (PL) evidence a well-structured near band edge emission (NBE) due to the recombination of free $(\mathrm{FX})$, surface $(\mathrm{SX})$ and donor bound $\left(\mathrm{D}^{0} \mathrm{X}\right)$ excitons. Among the most representative emission lines, the $3.31 \mathrm{eV}$ transition was found to occur in the stacking faults-free microrods. The luminescence behavior observed in $\mathrm{H}$ passivated samples suggests a closer relationship between this optical center and the presence of surface states.

Besides the unintentionally doped micro/nanocrystals, $\mathrm{ZnO} / \mathrm{Ag}$ and $\mathrm{ZnO} /$ carbon nanotubes (CNT) hybrid structures were processed by LAFD. The former aims at the incorporation of silver as a p-type dopant and the latter envisaging photovoltaic applications. Silver-related spherical particles were found to be inhomogeneously distributed at the microrods surface, accumulating at the rods tips and promoting the $\mathrm{ZnO}$ nanorods re-nucleation. Despite the fact that energy dispersive X-ray measurements suggest that a fraction of the silver could be incorporated in the $\mathrm{ZnO}$ rods, no new related luminescence lines or bands were observed when compared with the as-grown samples. For the case of the $\mathrm{ZnO} / \mathrm{CNT}$ composites two main approaches were adopted: i) a direct deposition of $\mathrm{ZnO}$ particles on the surface of vertically aligned multi-walled carbon nanotubes (VACNTs) forests without employing any additional catalyst and ii) new $\mathrm{ZnO} / \mathrm{CNT}$ hybrids were developed as buckypaper nanocomposites. The use of the LAFD technique in the first approach preserves the CNTs structure and alignment and avoids the collapse of the VACNTs array, which is a major advantage of this method. On the other hand, LAFD grown $\mathrm{ZnO}$ nanoparticles and tetrapods were used to produce $\mathrm{ZnO} / \mathrm{CNT}$ buckypaper nanocomposites. When compared with the as-grown samples the PL spectra of the composites structures behave differently. For the case of the $\mathrm{ZnO} / \mathrm{VACNTs}$ no changes on the peak position and spectral shape were observed. Only an enhancement of the overall luminescence was found to occur. On contrary, for the buckypaper nanocomposites notable changes on the spectral shape and peak position were observed, likely due to distinct surface band bending effects for the $\mathrm{ZnO}$ nanoparticles and tetrapods embedded in the CNTs.
\end{abstract}

Keywords: $\mathrm{ZnO}, \mathrm{LAFD}, \mathrm{Ag}, \mathrm{ZnO} / \mathrm{CNTs}$, optical properties, structural properties

Oxide-based Materials and Devices V, edited by Ferechteh H. Teherani, David C. Look,

David J. Rogers, Proc. of SPIE Vol. 8987, 89871F - @ 2014 SPIE

CCC code: $0277-786 X / 14 / \$ 18 \cdot$ doi: $10.1117 / 12.2039907$

Proc. of SPIE Vol. $898789871 \mathrm{~F}-1$ 


\section{INTRODUCTION}

$\mathrm{ZnO}$ is a wide band gap semiconductor $\left(\mathrm{E}_{\mathrm{g}} \sim 3.4 \mathrm{eV}\right.$ at low temperature $\left.{ }^{1}\right)$ that has been extensively studied in the past decades due to its important applications. The study of this oxide matrix started several decades ago but the renewed interest lies in the change of its properties when produced at the nanoscale. It is a key technological material which is considered a good alternative to gallium nitride $(\mathrm{GaN})$ essentially due to its higher exciton binding energy, higher damage resistance ${ }^{2}$, the ability to be grown in numerous and cheaper substrates, and by the simpler growth technology 1,3 . This material is suitable for short-wavelength optoelectronic applications ${ }^{4,5}$, energy storage devices, field emission displays ${ }^{6}$, solar cells ${ }^{7}$, chemical ${ }^{8}$ and biological sensors ${ }^{9}$, among other applications. In addition, $\mathrm{ZnO}$ is a versatile material that can be grown in several morphologies and by a large number of techniques, which include colloidal synthesis ${ }^{10}$, chemical vapor deposition ${ }^{11}$, pulsed laser deposition ${ }^{12}$, molecular beam epitaxy ${ }^{13}$, thermal evaporation ${ }^{14}$, among others.

In addition, the $\mathrm{ZnO}$ potential for some applications can also be improved by forming hybrid structures. Thus, the synergetic combination with metallic nanoparticles ${ }^{15}$ have been intensively investigated due to the possibility of the modulation of their properties ${ }^{16}$. The research on the modification of semiconductors with noble metal ions, as is the case of silver or gold, has gained a significant interest in different areas like photocatalysis, sensing, surface-enhanced Raman or biomedicine ${ }^{16}-^{18}$. Among the different metals $\mathrm{Ag}$ has demonstrated a great potential in different areas such as photocatalysis ${ }^{15}$ or antibacterial ${ }^{19},{ }^{20}$ applications especially when combined with $\mathrm{ZnO}$ structures. This semiconductor also demonstrates photacaltalytic and antibacterial activities by itself, so an enhancement on its performance in such applications is expected when combined with silver. One of the most important limitations of the $\mathrm{ZnO}$ nanostructures to achieve high photocaltalytic efficiency is the high recombination rate of photoinduced charge carriers. One efficient method to overcome this problem is to deposit noble metals, as silver, on the surface of the semiconductor ${ }^{19}$. The photogenerated electrons are then transferred from the conduction band to the metal particle while the holes remain in the semiconductor surface, improving the charge separation and thus the photocatalytic efficiency ${ }^{19}$. Furthermore, since $\mathrm{Ag}$ is a group 11 (I-b) element, $\mathrm{Ag}$ doping has been reported as a possible way to form acceptor states in $\mathrm{ZnO}$, if the $\mathrm{Ag}$ ion occupies a substitutional $\mathrm{Zn}$ site $\left(\mathrm{Ag}_{\mathrm{Zn}}\right)$, therefore achieving p-type conductivity ${ }^{21}{ }^{24}$. However, $\mathrm{Ag}$ is considered to have a low solubility in $\mathrm{ZnO}$ at equilibrium conditions, since the $\mathrm{Ag}$ ion has a different valence state than $\mathrm{ZnO}$ and a larger ionic radius, so diffusion of the $\mathrm{Ag}$ to the surface of the $\mathrm{ZnO}$ is frequently observed ${ }^{25}$. The production of this type of $\mathrm{ZnO} /$ metal composites usually involves procedures as calcination, sputter or electrophoretic deposition of metals in the $\mathrm{ZnO}$ surfaces ${ }^{18}$. In most of these cases several steps are needed in order to produce the composites. The recently developed LAFD method offers the advantage of synthesizing the silver nanoparticles directly on the surface of the $\mathrm{ZnO}$ structures in a single step ${ }^{26}$.

On the other hand, the combination of the optoelectronic properties of $\mathrm{ZnO}$ with the mechanical, thermal and electrical properties of carbon nanotubes (CNTs) ${ }^{27}$ could give rise to structures that are potential candidates for advanced functional applications. Namely, combining nanostructures of $\mathrm{ZnO}$ with CNTs in order to incorporate them as the active area for dye-sensitized solar cells (DSSCs) can improve the performance of the cells by providing a good electrical conductivity to $\mathrm{ZnO}$ and increasing the contact between the $\mathrm{ZnO}$ structures and the anode substrate ${ }^{28}$. Earlier works already proved that the UV-induced photoconductive behavior and the photocurrent generation of $\mathrm{ZnO} / \mathrm{CNTs}$ structures revealed functional interaction between both phases giving a quantum efficiency of $1 \%$ in unbiased photoconductivity measurements ${ }^{29}$. The $\mathrm{ZnO} / \mathrm{CNT}$ heterojunctions can have a charge transfer efficiency of up to $90 \%$. Additionally, the $\mathrm{ZnO}$ intrinsic recombination of photoinduced electron-hole pairs is reduced, enhancing charge separation and transport properties $^{30}$.

For the production of these structures different techniques have been employed, like chemical vapor deposition ${ }^{29}$, sputtering ${ }^{31}$, vapor phase transport ${ }^{6}$ or atomic layer deposition ${ }^{32}$. Previous studies showed that laser assisted flow deposition (LAFD) offers some advantages in the deposition of $\mathrm{ZnO}$ nanostructures onto vertically aligned carbon nanotubes (VACNTs) arrays since it allows the synthesis of $\mathrm{ZnO}$ in a single step directly on top of the VACNTs preserving their structure and alignment ${ }^{33}$.

In this work we review the growth of $\mathrm{ZnO}$ samples by the LAFD technique. This method proved to be very efficient, offering high growth rates for the large-scale production of $\mathrm{ZnO}$ micro and nanocrystals. Structural and optical characterization revealed the high crystalline and optical quality of the produced crystals. In the case of $\mathrm{ZnO}$ samples 
grown in the presence of silver ( $\mathrm{ZnO} /$ metal composites), most of the silver is found in small droplets on the microrods surface and no incorporation inside the crystals can be demonstrated by electron techniques characterization. Additionally, the Ag distribution is not uniform in the samples. Luminescence studies showed that the optical emission of the samples is independent of presence of silver on the $\mathrm{ZnO}$ surface. The LAFD was used to grow $\mathrm{ZnO}$ particles on the top of VACNTs and $\mathrm{ZnO} / \mathrm{CNTS}$ nanocomposites in the form of buckypapers were also produced. No changes on the peak position and spectral shape were observed in the former case while for the latter the peak position and shape of the luminescence shows a strong dependence on the samples morphology pointing to distinct surface band bending effects for the $\mathrm{ZnO}$ nanoparticles and $\mathrm{ZnO}$ tetrapods embedded in the CNTs.

\section{EXPERIMENTAL DETAILS}

\subsection{MATERIALS SYNTHESIS}

\subsubsection{LAFD GROWTH OF ZnO}

The LAFD was performed on a modified laser floating zone (LFZ) growth chamber which comprises a $200 \mathrm{~W} \mathrm{CO}_{2}$ laser (Spectron) coupled to a reflective optical set-up producing a circular crown-shaped laser beam. The LAFD method is based on a solid/vapor mechanism. The beam is focused on the tip of the extruded cylindrical rods, previously prepared by mixing the $\mathrm{ZnO}$ powders (AnalaR, 99.7\%) with polyvinyl alcohol (PVA, 0.1 g.mll ${ }^{-1}$, Merck). The substrates are placed on a sample holder attached to the upper spindle of the LFZ system, above the feed rod as previously described ${ }^{33}$.

Due to its high vapor pressure and to the fact that $\mathrm{ZnO}$ decomposes into its atomic components at the melting temperature $\left(1977^{\circ} \mathrm{C}\right)$ at atmospheric pressure, the flux methods have been extensively studied ${ }^{34}$. LAFD proved to be a very efficient method to grow $\mathrm{ZnO}$ samples with high crystalline and optical quality ${ }^{26},{ }^{33},{ }^{35}$. This is a flux method that combines local heating generated by the high power laser focused on the precursor with the thermal decomposition of $\mathrm{ZnO}$ at its melting temperature. The generated gases are transferred to the low temperature regions, after the reaction of the zinc with the oxygen to form $\mathrm{ZnO}$ products. Different $\mathrm{ZnO}$ morphologies (microrods, nanoparticles and tetrapods) can be obtained in the as-grown samples as a result from different kinetics/thermodynamics local conditions verified in different regions of the growth chamber ${ }^{35}$. In the region near the top of the precursor rod the temperature is higher than at the sample holder and there is a permanent air circulation conducting to the formation of bigger crystals. In the sample holder region smaller crystals are formed, some of them with nanometric sizes while the crystals formed at the top of the rod show dimensions on the micrometer scale. With an accurate choice of the growth parameters such as the laser power (heating power) and atmosphere it is possible to control the dimensions and shape of the produced crystals. Moreover, with this technique it is possible to incorporate other compounds in the rod precursors in order to dope the $\mathrm{ZnO}$ crystals or to form hybrid structures in a single step growth as was already reported for $\mathrm{ZnO}$ samples grown in the presence of silver ${ }^{26}$. 


\subsubsection{CVD DEPOSITION OF VACNTS}

Vertically aligned CNTs (VACNTs) were synthesized by an optimized catalyst-supported chemical vapor deposition (CVD) technique. Prior to the synthesis step, the 2 inch diameter p-type $\mathrm{Si} / \mathrm{SiO} 2$ wafer (Siegert Consulting) substrates for the CNT growth were coated with a bilayer of $\mathrm{Al}_{2} \mathrm{O}_{3}(10 \mathrm{~nm}) / \mathrm{Fe}(1 \mathrm{~nm})$, by magnetron sputtering. Then, the Fe film was converted into nano-sized particles $(\sim 20 \mathrm{~nm})$ with a round shape morphology and a uniform density $\left(\sim 10^{10}\right.$ particles $\left.\mathrm{m}^{-2}\right)$ by means of in situ annealing inside the CVD reactor at $770^{\circ} \mathrm{C}$, under a reductive gas flow of $\mathrm{H}_{2} / \mathrm{Ar}(500 / 200 \mathrm{sccm})$. Subsequently, the $\mathrm{H}_{2}$ and $\mathrm{Ar}$ flows were adjusted to 400 and $100 \mathrm{sccm}$ respectively, and a $\mathrm{C}_{2} \mathrm{H}_{2}$ flow $(10 \mathrm{sccm})$ was added for 15 min to yield the Fe-catalyzed growth of VACNTs with diameter and length sizes of $\sim 15 \mathrm{~nm}$ and $\sim 1.5 \mathrm{~mm}$, respectively, on large areas ${ }^{36}$.

\subsubsection{PREPARATION OF ZnO/CNTS COMPOSITE BUCKYPAPERS}

Functionalized multi-walled carbon nanotubes (NC3101), provided by Nanocyl supplier, were used to prepare the $\mathrm{ZnO} / \mathrm{CNT}$ composite buckypapers. The CNTs have average length and diameter sizes of $1.5 \mu \mathrm{m}$ and $9.5 \mathrm{~nm}$, respectively, with a purity level of $95 \mathrm{wt} . \%$ and a $4 \mathrm{wt} . \%$ content of covalently bonded carboxylic groups (-COOH).

$\mathrm{ZnO} / \mathrm{CNT}$ composite buckypapers with a weight ratio of $4: 1$ were prepared in isopropyl alcohol (IPA, $\geq 99.8 \%$, SigmaAldrich) following five main steps: (1) Solo CNT suspensions of $0.1 \mathrm{~g} .1^{-1}$ start to be processed by high-speed shearing for 15 min (IKA T25-Ultra-Turrax, working at 20,500 rpm) with a shearing force of $96 \mathrm{~Pa}$ to eliminate big CNT agglomerates; (2) Subsequently, the CNT suspension was sonicated (Selecta, working at $60 \mathrm{kHz}, 200 \mathrm{~W}$ ) for 60 min to yield mixtures of individualized CNTs and small sized agglomerates $(<3 \mu \mathrm{m})^{37}$. Simultaneously, both the suspensions of $\mathrm{ZnO}$ tetrapods and nanoparticles with a fixed concentration of $1 \mathrm{~g} .1^{-1}$ each were sonicated in the same conditions of those of the CNT suspension to deagglomerate softly possible $\mathrm{ZnO}$ clusters. (3) Afterwards, the suspensions were mixed together, respecting the weight ratio referred above, and sonicated during $15 \mathrm{~min}$ to promote interactions of individual $\mathrm{ZnO}-\mathrm{CNT}$ particles. (4) The $\mathrm{ZnO} / \mathrm{CNT}$ suspension was then dropped in a cylindrical mould of $10 \mathrm{~mm}$ of diameter placed onto a $0.22 \mu \mathrm{m}$ pore size filter (hydrophobic PTEF, Millipore) to produce $\mathrm{ZnO} / \mathrm{CNT}$ buckypapers by vacuum filtration. This was accomplished by coupling a rotary vacuum pump to a filter-Büchner funnel-Kitasato flask setting. For each CNT membranes of $10 \mathrm{~mm}$ of diameter and about $12 \mathrm{ml}$ of suspension was used. (5) Finally, the membranes were dried in an oven at $80^{\circ} \mathrm{C}$ for $15 \mathrm{~min}$.

\subsection{STRUCTURAL AND OPTICAL CHARACTERIZATION}

Steady state photoluminescence (PL) was generated using the $325 \mathrm{~nm}$ light from a cw He-Cd laser and an excitation power density less than $0.6 \mathrm{~W} \mathrm{~m}^{-2}$. The samples were mounted in a cold finger of a closed-cycle helium cryostat and the sample temperature was controlled in a range from $14 \mathrm{~K}$ to room temperature (RT). The luminescence spectra was acquired using a dispersive system SPEX 1704 monochromator $\left(1 \mathrm{~m}, 1200 \mathrm{~mm}^{-1}\right)$ fitted with a cooled Hamamatsu R928 photomultiplier tube. The samples morphology was characterized by scanning electron microscopy (SEM), (Hitachi SU70). The microstructure was analyzed by transmission electron microscopy (TEM), high resolution TEM (HRTEM) and high angle annular dark field scanning TEM (HAADF-STEM). Quantitative compositional analysis were performed by using an Oxford INCA Energy 2000 system for electron dispersive X-ray spectroscopy (EDS), using a probe size of about $1 \mathrm{~nm}$. All the measurements were carried out in a JEOL 1200 EX and a JEOL 2010F microscopes operating at 120 and $200 \mathrm{kV}$, respectively. Furthermore, the crystal structure of the $\mathrm{ZnO}$ microstructures was investigated by measuring $\theta-2 \theta$ scans of X-ray diffraction (XRD) using a PANalytical X'Pert PRO equipment $\left(\mathrm{CuK}_{\alpha}\right.$ radiation, $\left.\lambda=1.54056 \AA\right)$. Raman spectroscopy (Horiba Jobin Yvon HR800) was measured in backscattering configuration by exciting the samples with $532 \mathrm{~nm}$ (Ventus-LP-50085, Material Laser Quantum) and $632.8 \mathrm{~nm}$ laser lines. Micro Particle Induced X-ray Emission (PIXE) was performed using an Oxford Microbeams OM150 type scanning microprobe. This allowed to focus a $2.0 \mathrm{MeV}$ proton beam down to $3-4 \mu \mathrm{m}^{2}$ using a $100 \mathrm{pA}$ beam current. The produced X-rays were collected by a 80 $\mathrm{mm}^{2} \mathrm{Si}(\mathrm{Li})$ detector with a resolution of $145 \mathrm{eV}$ positioned at $135^{\circ}$ with the beam direction. The operation and basic data 
manipulation, including elemental distribution mapping, was achieved through the OMDAQ software code, and the quantitative analysis was done using the DAN32 application ${ }^{38}$.

\section{RESULTS AND DISCUSSION}

\section{1. $\mathrm{ZnO}$}

$\mathrm{ZnO}$ samples grown by LAFD technique were analyzed by SEM, denoting that, as aforementioned, this method leads to different $\mathrm{ZnO}$ morphologies depending on the region of the growth chamber where the products are formed. Micrographs of some as-grown samples are depicted in Figure 1. Essentially three different types of morphologies can be produced: nanoparticles (Figure 1a), tetrapods (Figure 1b and c) and microrods (Figure 1d). The nanoparticles present an equiaxial configuration with an average size around $100 \mathrm{~nm}$. These particles constitute the first layer of $\mathrm{ZnO}$ grown on the substrate surface and correspond to the initial heating stage of the growth process. The following layer consists of tetrapods. These are structures of tetrahedral shape with four branches which are extended from a central part. Most of the tetrapod branches exhibit a needle-like shape with the thickness decreasing from the central region to the tip of the branch. Dimensions from hundreds of nanometers (Figure 1b) to a few micrometers (Figure 1c) were measured. These two first types of morphologies correspond to the structures that are formed in the low temperature regions at the substrate. The $\mathrm{ZnO}$ rods (Figure 1d) are grown on the tip of the precursor rod. These crystals exhibit a high aspect ratio with hexagonal cross section and larger dimensions than the structures formed on the substrates. The microrods present lengths of several micrometers and diameters in the order of hundreds of nanometers. These different morphologies are formed during the same run of growth. Nonetheless, with an appropriate choice of the growth conditions, namely the laser power and the growth atmosphere, it is possible to control the growth of some of the morphologies. For instance, applying low laser powers $(\sim 20 \mathrm{~W})$ it is possible produce only nanoparticles avoiding the formation of tetrapods. On the contrary, high laser powers (high temperatures) lead to a predominant formation of tetrapods. These results are in agreement with the growth mechanism reported by Ronning et al. ${ }^{39}$. It is important to note that the rods on the tip of the precursor are only formed for high laser powers.
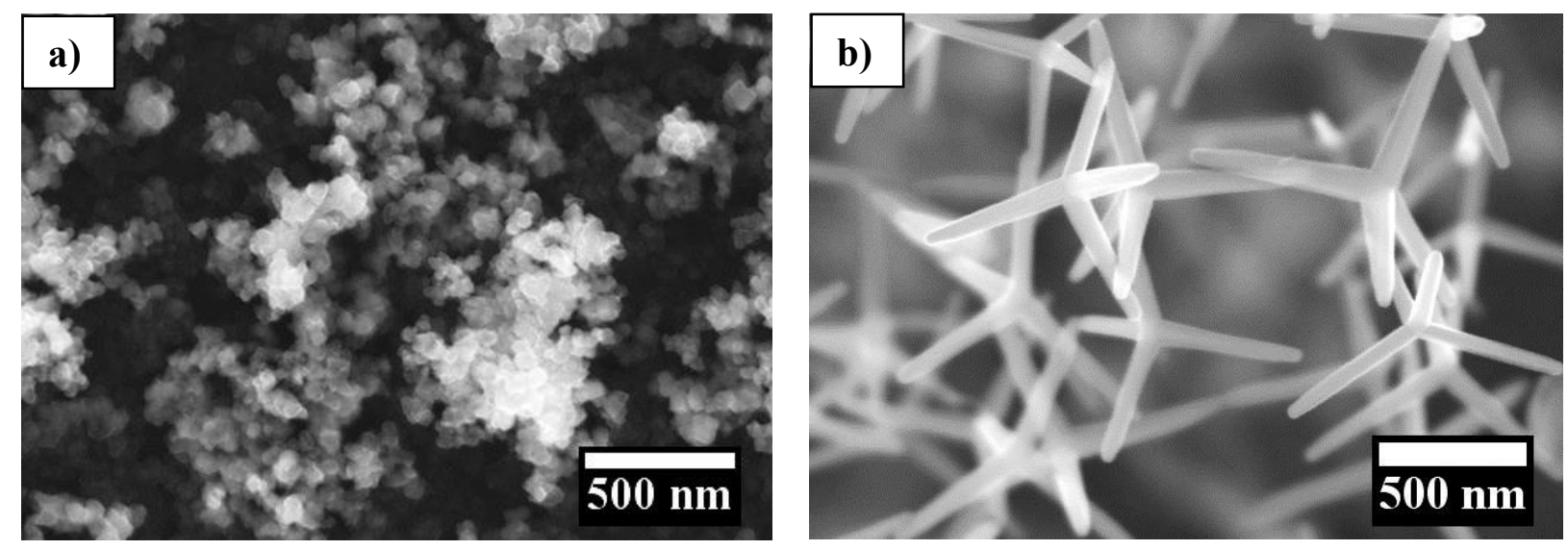

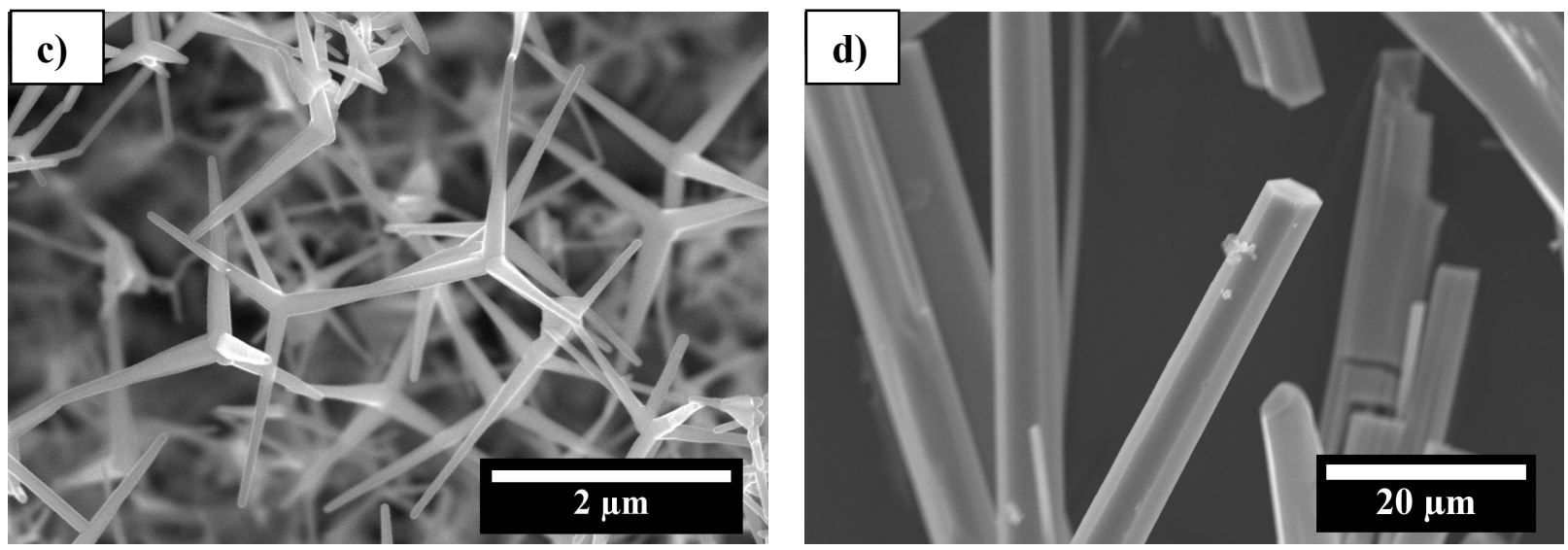

Figure 1 - SEM micrographs of the LAFD as-grown $\mathrm{ZnO}$ structures: a) nanoparticles, b) and c) tetrapods and d) microrods.

The XRD patterns of the different $\mathrm{ZnO}$ structures produced by the LAFD technique are shown in Figure 2. All the planes depicted in the diffraction pattern can be associated to the hexagonal wurtzite crystalline structure of $\mathrm{ZnO}$, highlighting the single phase nature of the produced samples. The XRD results put in evidence the high crystallinity of the samples.

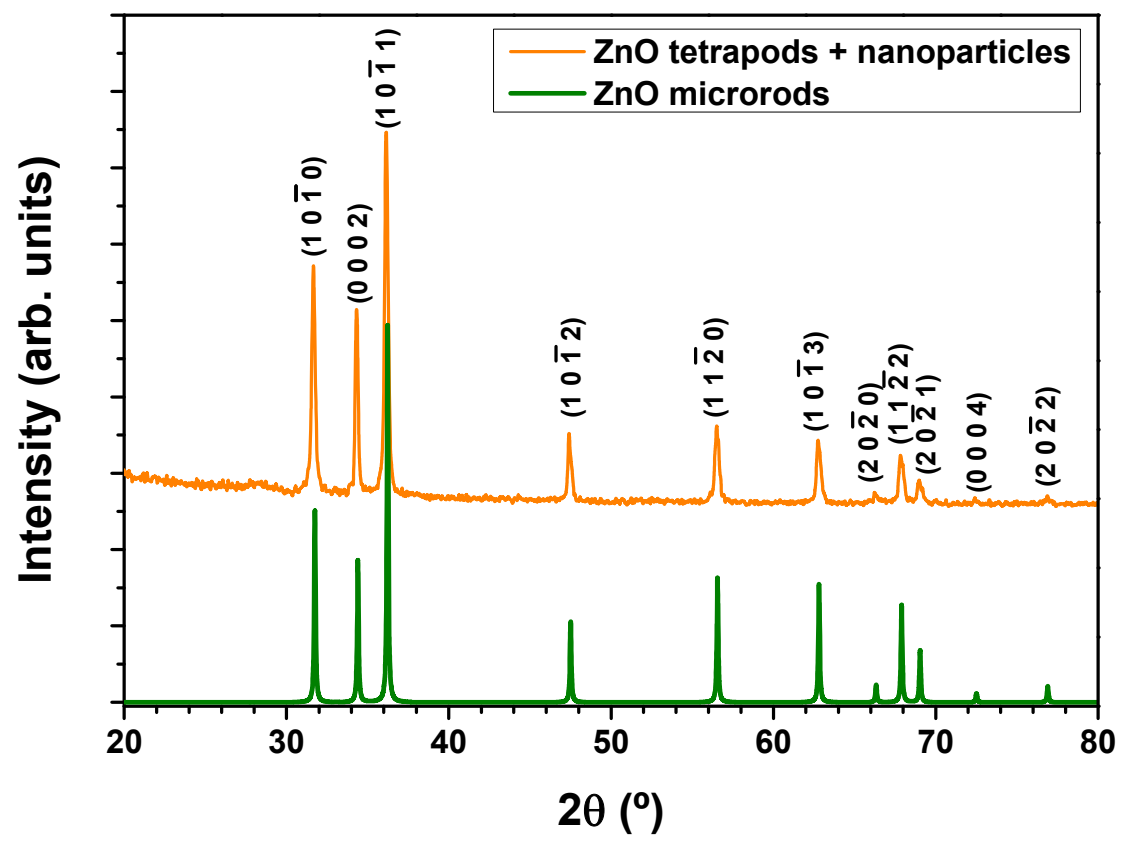

Figure 2 - XRD patterns of the $\mathrm{ZnO}$ structures grown by LAFD.

Figure 3a shows a HAADF-STEM image of one representative $\mathrm{ZnO}$ tetrapod. Based on the present Z-contrast image, where the intensities strongly depending on the atomic number $Z$, the composition seems to be uniform along the entire tetrapod, both in longitudinal and transversal directions. Likewise, HRTEM images of the analyzed tetrapods (see an example in Figure 3b) showed an excellent crystalline quality and no dislocations or stacking faults were found along the entire nanostructure. The inset of Figure $3 \mathrm{~b}$ corresponds to the Fast Fourier Transform (FFT) recorded from the tetrapod highlighted in Figure 3a. The FFT is consistent with the wurtzite structure of $\mathrm{ZnO}$ observed along the [0001] zone axis. Taking into account the orientation of tetrapod branch in the HRTEM image we conclude that the [11 $\overline{2} 0]$ is the typical crystallographic direction of the growth for this tetrapod branch. It is worth noting that the study of the crystalline structure was performed in the same way on $\mathrm{ZnO}$ microrod. HRTEM analyses (not shown here) showed also a good crystalline quality comparable to $\mathrm{ZnO}$ tetrapod. 

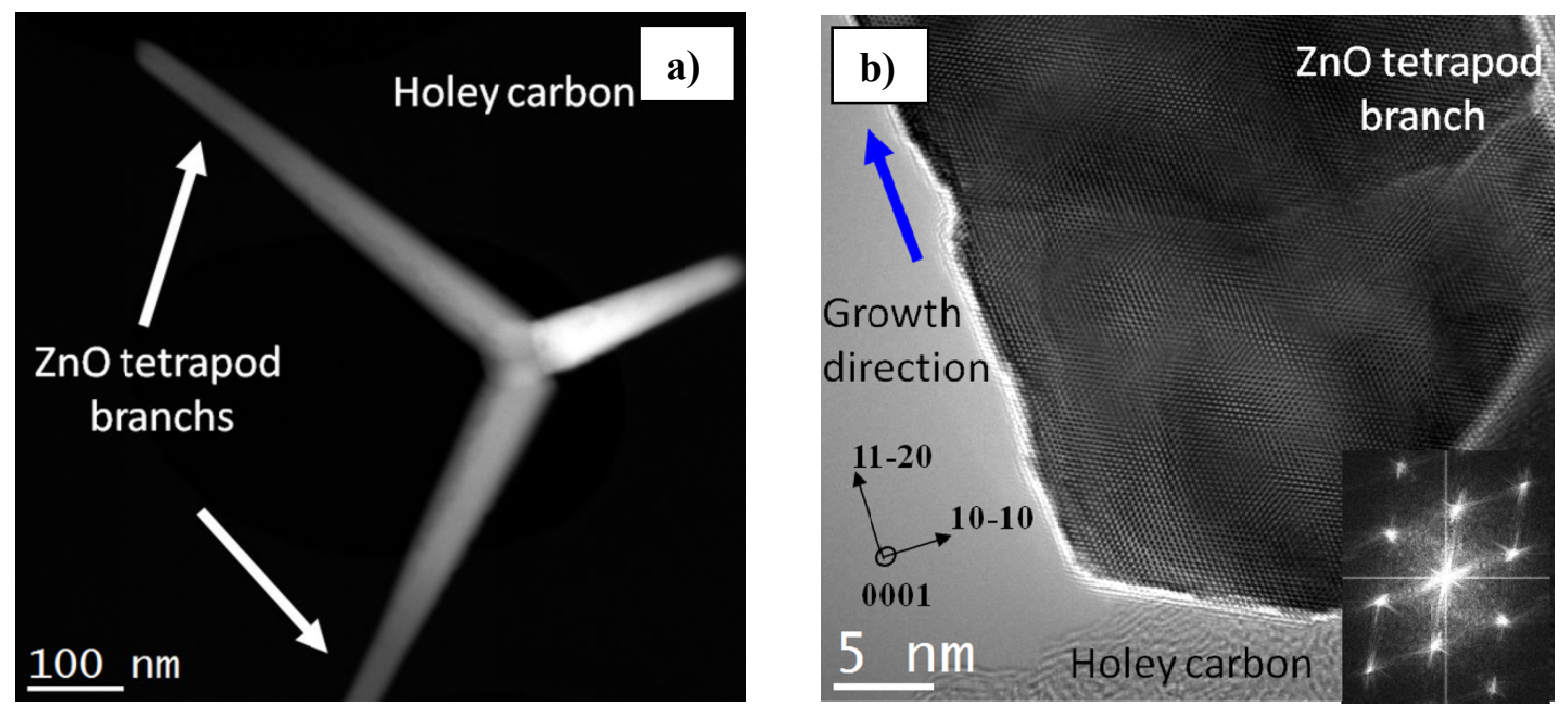

Figure 3 - a) HAADF-STEM image showing one representative ZnO tetrapod scraped from the substrate surface b) HRTEM images of a $\mathrm{ZnO}$ tetrapod branch. The Fast Fourier Transform of the inset reveals the wurtzite structure of $\mathrm{ZnO}$ along the [0001] zone axis.

The optical properties of the LAFD samples were studied by low temperature PL, as can be seen in Figure 4 and Figure 5. While the tetrapods emission (Figure 4) is dominated by the donor-bound excitons $\left(\mathrm{D}^{0} \mathrm{X}\right){ }^{40}{ }^{42}$ in the ultra-violet region and almost no visible luminescence is observed, in the case of the $\mathrm{ZnO}$ microrods (Figure 5) besides the near band edge recombination also the green broad band related to deep level defects is identified ${ }^{343},{ }^{44}$. Noteworthy, in addition to the free exciton (FX) and $\mathrm{D}^{0} \mathrm{X}$ recombination lines, the luminescence of these samples is dominated by a line peaked at $3.31 \mathrm{eV}$ followed by its longitudinal optical (LO) phonon replicas at $\sim 3.24 \mathrm{eV}$ and $\sim 3.16 \mathrm{eV}$, with an energy separation of $\sim 70 \mathrm{meV}$.

The $3.31 \mathrm{eV}$ line has been widely discussed in the literature and its nature is still under debate. Most of the wellestablished models to explain the optical properties of the $\mathrm{ZnO}$ were developed several decades ago ${ }^{43}, 45,46$ and plenty of important contributions have been added since then ${ }^{340},{ }^{47}-52$. In particular, in low dimensional structures, surface excitons (SX) have been observed and reported ${ }^{53},{ }^{54}$. One of the most argued optical centers corresponds to the aforesaid $3.31 \mathrm{eV}$ line, detected in all forms of $\mathrm{ZnO}$ structures and assigned to different recombination mechanisms, as recently reported by Thonke et al. ${ }^{49}, 55,56$. According with this author, the $3.31 \mathrm{eV}$ line is associated with an acceptor level at 0.13 $\mathrm{eV}$ above the zinc oxide valence band and the transition is related with the presence of stacking faults in the basal plane. Other hypotheses for the nature of this emission line have been addressed in the literature such as donor-valence band transitions, electron-hole recombination from donor-acceptor pairs (DAP), electron-acceptor transitions, recombination of excitons bound to deep neutral acceptors, two electron satellite of $\mathrm{D}^{0} \mathrm{X}$, surface excitonic contribution, among others ${ }^{49}{ }^{57}$. Regardless of its nature it should be pointed out that the HRTEM analysis of microrods samples did not reveal any evidence suggesting the presence of stacking faults. Furthermore, the luminescence intensity of the $3.31 \mathrm{eV}$ line was found to be strongly dependent of the excitation density and surface passivation treatments. The latter suggests a closer relationship between this optical center and the presence of surface states. Particularly, the surface passivation with hydrogen plasma leads to the increase of the intensity of the $\mathrm{D}^{0} \mathrm{X}$ transition at the expense of the $3.31 \mathrm{eV}$ line (inset of Figure 5) indicating that $\mathrm{H}$, which diffuses at very low temperatures, plays a crucial role either in surface passivation and/or as a shallow donor, as already pointed out by other authors ${ }^{58}$. 


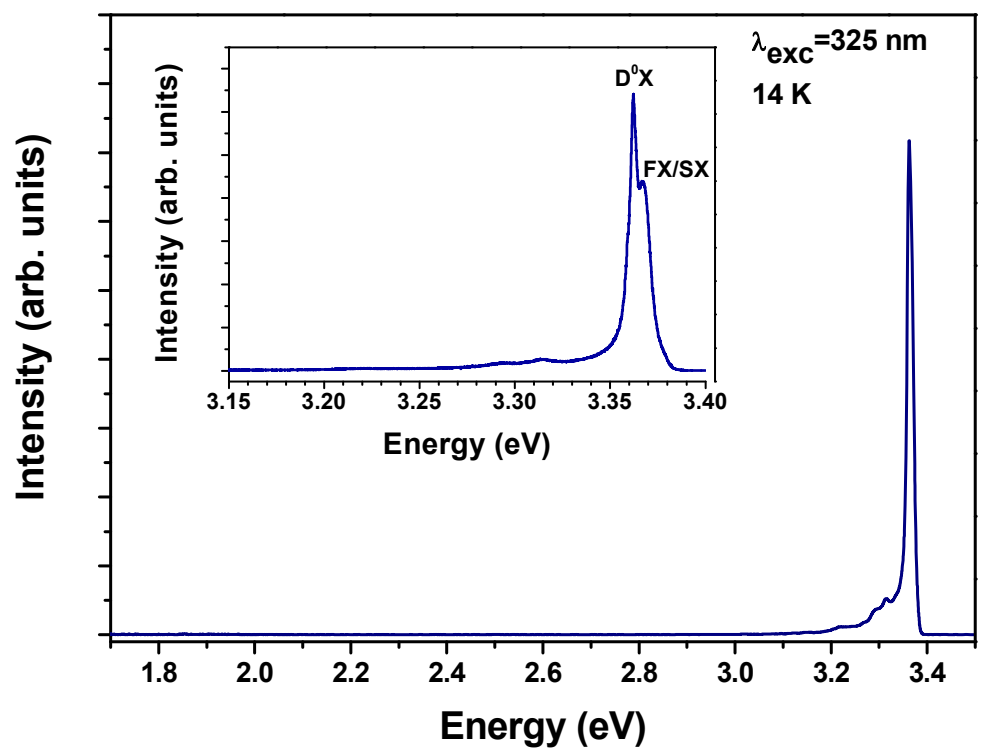

Figure 4 - Low temperature PL spectrum of the ZnO tetrapods. The inset corresponds to a high resolution spectrum of the NBE emission.

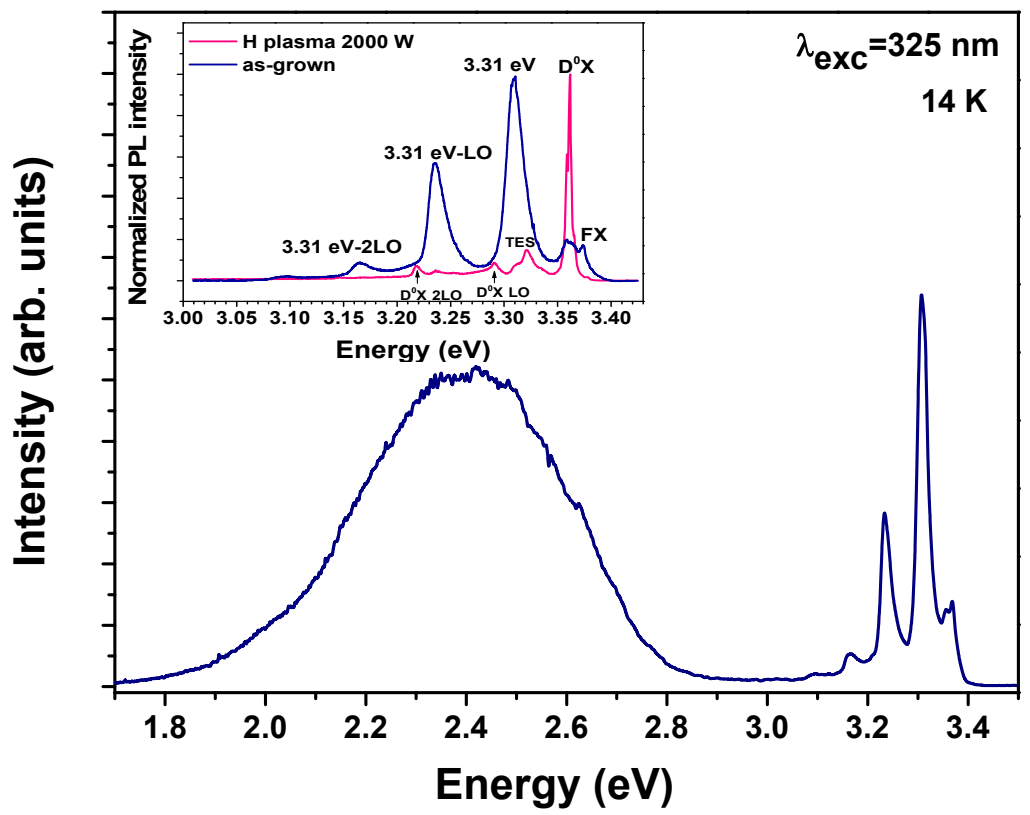

Figure 5 - Low temperature PL spectrum of the $\mathrm{ZnO}$ microrods. The inset corresponds to a high resolution spectrum of the NBE emission for the $\mathrm{ZnO}$ before and after the treatment with $\mathrm{H}$ plasma.

\subsection{ZnO SAMPLES GROWN IN THE PRESENCE OF Ag}

The usefulness of the LAFD method for the growth of hybrid structures was tested with the system $\mathrm{ZnO} / \mathrm{Ag}$. The addition of the silver in the $\mathrm{ZnO}$ precursors has as main aims the study of the samples morphology what has a great influence on possible bio applications and/or toxicity studies, and determination of the silver incorporation on the $\mathrm{ZnO}$ host as a potential acceptor element. In the case of the samples grown in the presence of silver, different amounts of $\mathrm{AgNO}_{3}(0.1,0.5,1.0$ and $2.0 \mathrm{~mol} \%)$ were added to the precursor rods. The samples were grown in air atmosphere at 35 
$\mathrm{W}$ of laser power. The study was performed on the microrods. The $\mathrm{ZnO} / \mathrm{Ag}$ samples were first analyzed by SEM and the micrographs are shown in Figure 6. As previously reported ${ }^{26}$ the samples exhibit randomly oriented $\mathrm{ZnO}$ rods with spherical Ag droplets deposited on their surface. These particles accumulate preferentially on the tips of the rods and for higher silver concentrations a re-nucleation is promoted. As evidenced in Figure 6 the Ag particles act as a catalyst for the $\mathrm{ZnO}$ growth in case of sample grown with $2.0 \mathrm{~mol} \% \mathrm{of} \mathrm{Ag}$, were the tips of the bigger rods are covered with new $\mathrm{ZnO}$ rods.
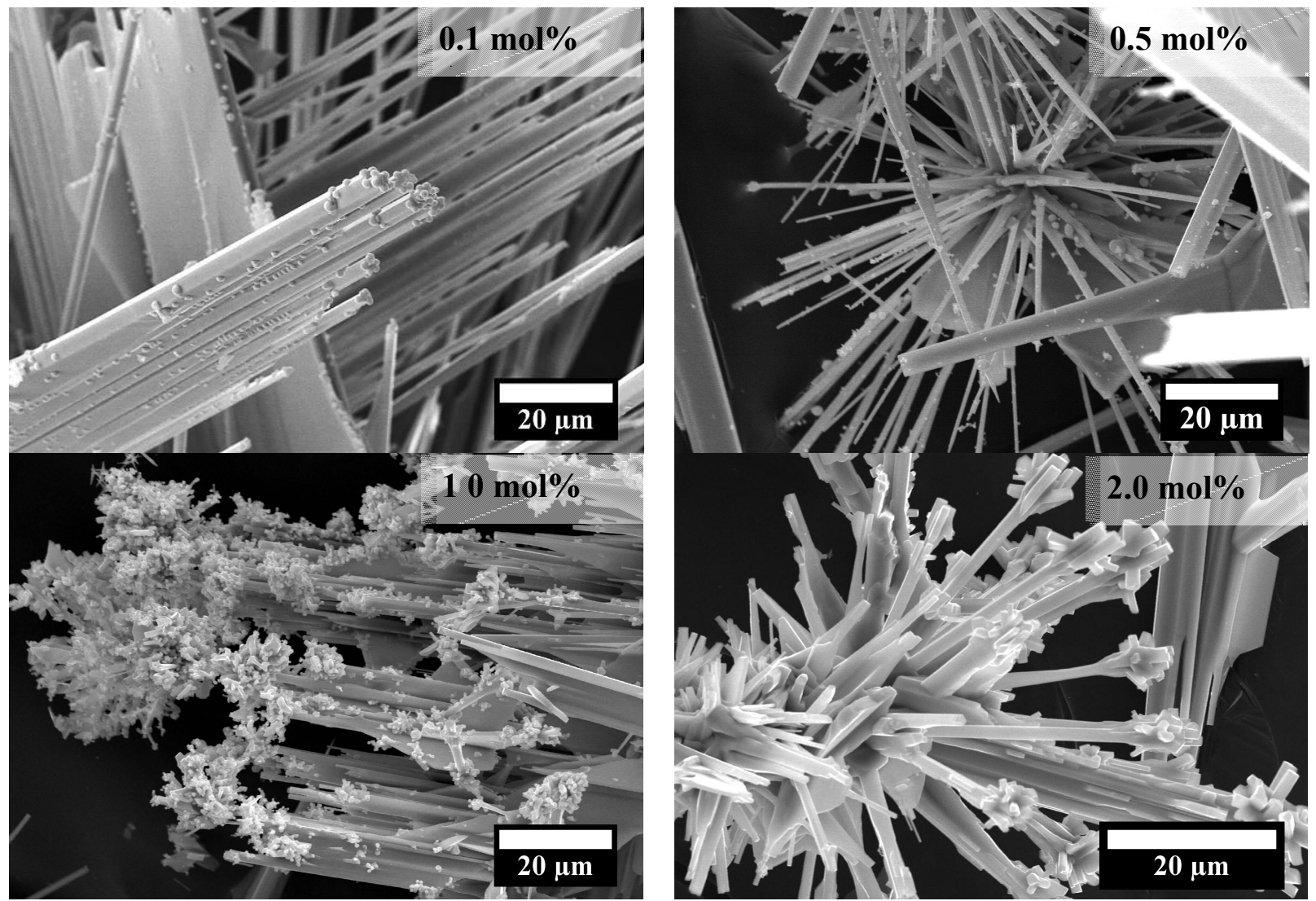

Figure 6 - SEM micrographs of the ZnO rods grown in the presence of different amounts of silver. Spherical droplets of metallic silver are observed at the surface of the rods, causing the re-nucleation of the $\mathrm{ZnO}$ rods when a higher silver concentration is present.

As in the case of the as-grown $\mathrm{ZnO}$ structures highlighted in the previous subsection, XRD and Raman (Figure 7) measurements demonstrate the hexagonal wurtzite crystalline structure for the $\mathrm{ZnO}$ rods in the hybrid $\mathrm{ZnO} / \mathrm{Ag}$ system. All the samples lead to a similar X-ray diffraction patterns with narrow diffraction lines, as reported before for the samples grown without Ag. Besides the $\mathrm{ZnO}$ crystalline structure, the XRD pattern (Figure 7a) shows a small contribution of $\mathrm{Ag}$ related diffraction maxima. While the peak at $\approx 44.3^{\circ}$ is clearly attributed to the metallic $\mathrm{Ag}(200)$, the peak at $\approx 38.1^{\circ}$ can be associated either with $\mathrm{Ag}(111)$ or $\mathrm{Ag}_{2} \mathrm{O}(200){ }^{59}$ suggesting that silver oxide phase can be promoted under the growth conditions used.

Raman spectra recorded with the $532 \mathrm{~nm}$ line as excitation source showed all the characteristic vibrational modes of the $\mathrm{ZnO}$ wurtzite structure that are active in Raman, $\mathrm{A}_{1}, \mathrm{E}_{1}$ and $\mathrm{E}_{2}$, as well as its overtones and combined modes were identified ${ }^{60},{ }^{61}$ (Figure 7b). The differences observed in the relative intensity of the vibrational modes can be attributed to polarization effects due to the different orientations of the $\mathrm{ZnO}$ crystals regarding incidence wave vector of the laser beam. 

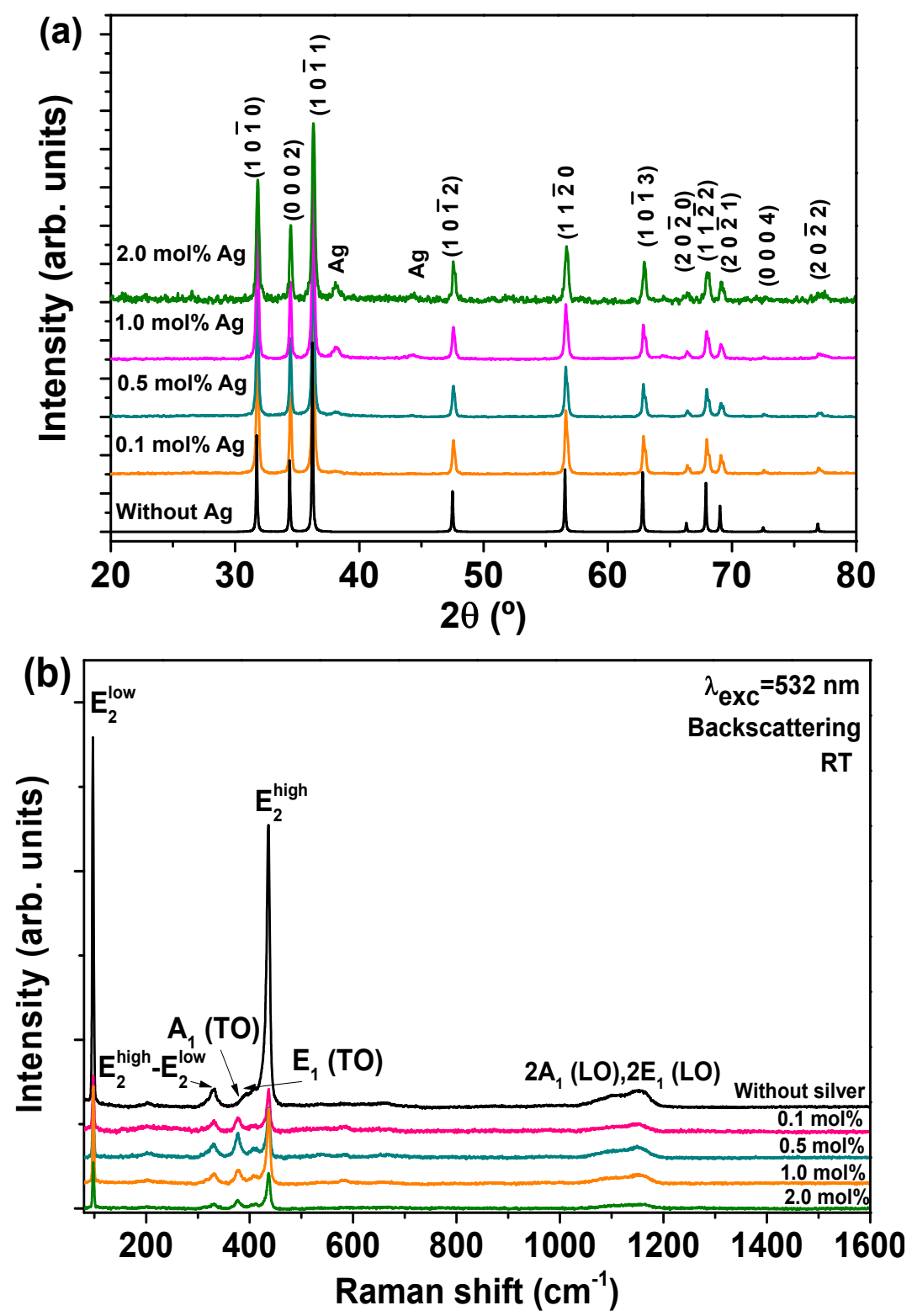

Figure 7 - (a) XRD patterns and b) Raman spectra of the $\mathrm{ZnO}$ rods acquired with $532 \mathrm{~nm}$ excitation showing their wurtzite structure. The XRD patterns indicate the presence of metallic silver.

The sample grown with $2.0 \mathrm{~mol} \%$ of Ag was further analyzed by TEM. As previously evidenced by the SEM micrographs some $\mathrm{ZnO}$ rods appear without silver droplets at its surface. In some of that free-particle $\mathrm{ZnO}$ rods, compositional analysis by EDX reveal low (around 2\%) Ag signals, which are likely to be related with silver located inside the $\mathrm{ZnO}$ lattice. Previous results ${ }^{26}$ obtained by the analysis of the XRD patterns already have suggested the $\mathrm{Ag}$ incorporation in $\mathrm{ZnO}$ using the present growth technique. In the case of $\mathrm{ZnO}$ rods with Ag particles, two particles family could be differentiated by their dimensions, as it can be seen in Figure 8. The larger particles, with dimensions around $500 \mathrm{~nm}$, can be found mainly in the bigger rods. It seems that they could be the origin of the promotion of the lateral $\mathrm{ZnO}$ growth, as stated before by the SEM results. The secondary nucleation of the $\mathrm{ZnO}$ rods on the Ag particles is appreciated in Figure 8a and 8b where Ag particles appear on the top of the growing rod. These particles were analyzed by EDX (far from the $\mathrm{ZnO}$ rods) and showed $\mathrm{Ag}$ and $\mathrm{O}$ signals with a stoichiometry close to the one of $\operatorname{Ag}_{2} \mathrm{O}$ phase. Along the re-nucleated rod the particle has left a footprint of silver where the percentage of Ag decreases from the top of the rod (were the $\mathrm{Ag}_{2} \mathrm{O}$ particle is placed) to the bottom. Besides these big particles, small $\mathrm{Ag}$ particles appear attached to the rod surface with sizes ranging between $15-25 \mathrm{~nm}$ (Figure $8 \mathrm{c}$ and d). Though due to the proximity of the $\mathrm{ZnO}$ 
matrix it is difficult to obtain reliable compositional analysis of these particles, the atomic percentage of Ag never overcomes the $60 \%$ of content. Nevertheless, the interplanar distances measured in FFT corresponding to the particle did not correspond to $\mathrm{ZnO}$ or $\mathrm{AgO}_{2}$ phases, so further analyses are required to ascertain about its nature.
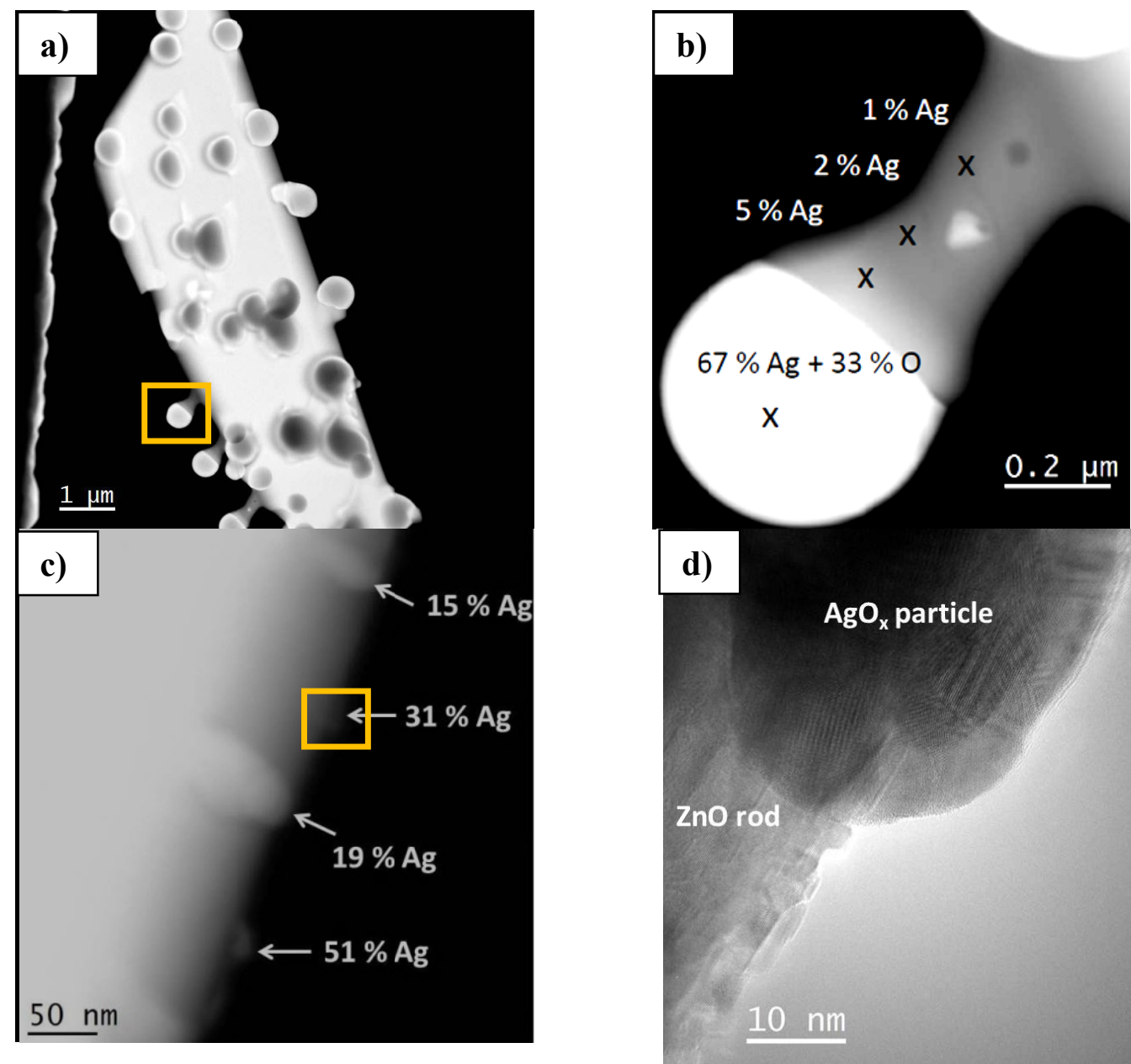

Figure 8- (a) HAADF-STEM image showing silver particles and re-nucleated nanorods covering the surface of a $\mathrm{ZnO}$ microrod. (b) Higher magnification image of the squared area in (a) highlighting the formation of new nanorods from the microrod side walls. The compositional analysis carried out by EDX spectroscopy confirmed that the large particles present at the nanorod tip were made up of $\mathrm{Ag}_{2} \mathrm{O}$. c) HAADF-STEM image showing smallest particles containing different amounts of Ag deposited on the surface of a $\mathrm{ZnO}$ microrod. d) HRTEM image showing the side wall of the $\mathrm{ZnO}$ microrod of the squared area in c).

Additional compositional measurements were accomplished by particle induced X-ray emission (PIXE) maps as shown in Figure 9. PIXE analysis corroborate the SEM and TEM results showing that also at a macroscopic scale the Ag is not homogeneously distributed in the $\mathrm{ZnO}$ rods, revealing some points with pure $\mathrm{ZnO}$ (point 1 ) and others with a higher content of silver than the nominal one (point 3 with $\sim 16 \mathrm{~mol} \% \mathrm{Ag}$ ). Some rods with hollow core were also detected (point 2). The average Ag content in the maps scales with the nominal values added to the precursor rods. In the case of the samples with $0.5 \mathrm{~mol} \%, 1.0 \mathrm{~mol} \%$ and $2.0 \mathrm{~mol} \% \mathrm{Ag}$ nominal values average amounts of $0.7 \mathrm{~mol} \%, 1.9 \mathrm{~mol} \%$ and $2.7 \mathrm{~mol} \% \mathrm{Ag}$ were measured.

Regarding the low temperature PL spectra of the hybrid $\mathrm{ZnO} / \mathrm{Ag}$ structures (Figure 10) no additional lines were observed when a comparison is made with the as-grown microrods. However, it should be pointed out that in similar samples also grown at lower temperatures ${ }^{26}$ the relative intensity of the $3.31 \mathrm{eV}$ line versus the $\mathrm{D}^{0} \mathrm{X}$ transition is reversed highlighting the role of the growth temperature in the revelation of the $3.31 \mathrm{eV}$ center. Despite the fact that EDX measurements 
suggest that a fraction of the silver is incorporated in the $\mathrm{ZnO}$ rods no new luminescence lines or bands were observed, suggesting that with the used conditions Ag does not create optically active defects in the UV-visible range. A similar result (not shown here) was observed for thin films intentionally Ag implanted with fluences ranging from $10^{13}$ and $10^{15}$ ions $/ \mathrm{cm}^{2}$ and thermally annealed. In this case no other transitions besides the $\mathrm{FX}, \mathrm{D}^{0} \mathrm{X}, 3.31 \mathrm{eV}$ and green band were found to occur in the same spectral region.

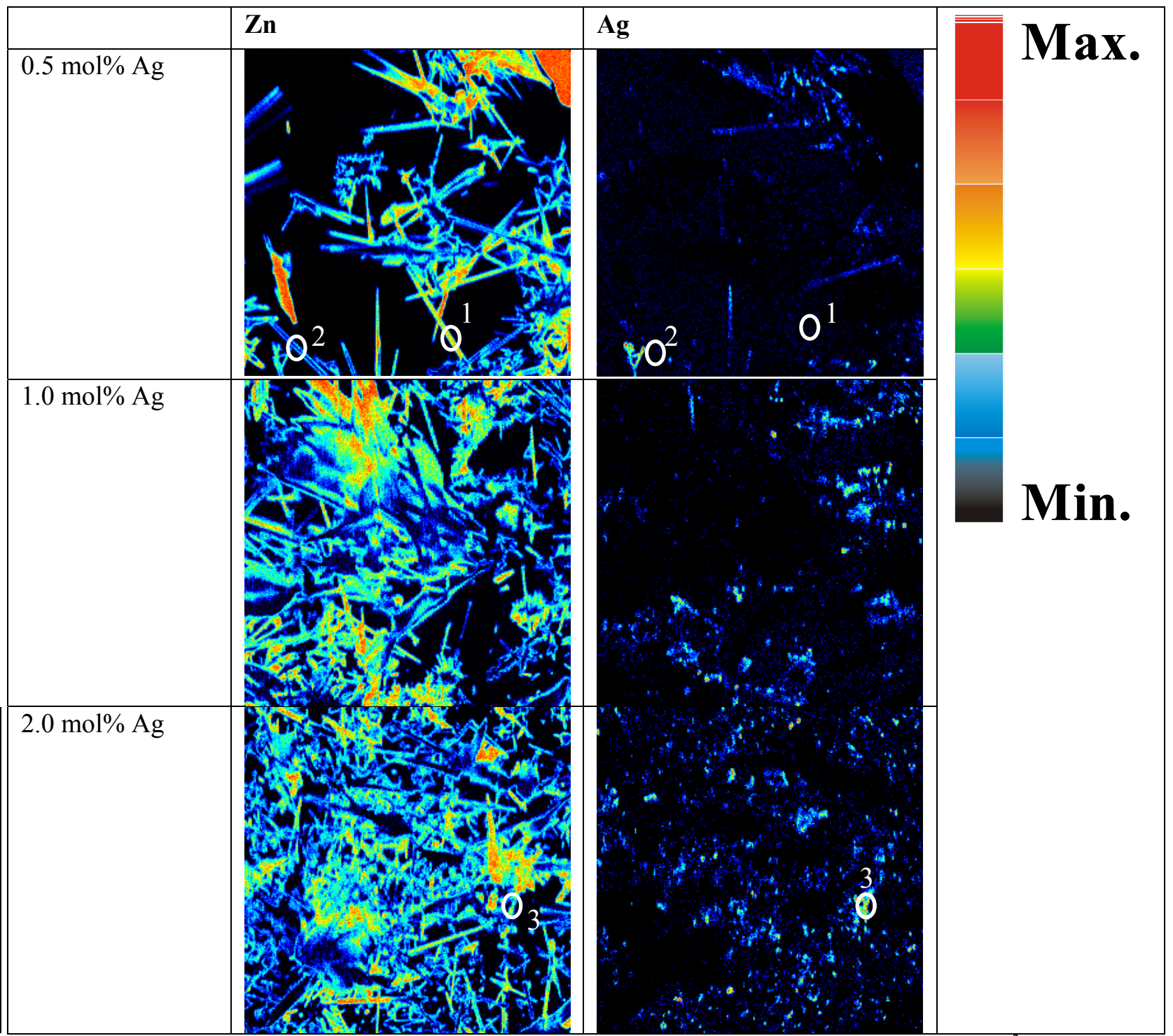

Figure 9 - PIXE analysis of the samples grown with 0.5, 1.0 and $2.0 \mathrm{~mol} \% \mathrm{Ag}$ acquired within a $1320 \mathrm{x} 1320 \mu \mathrm{m}^{2}$ area and using a $\sim 3-$ $4 \mu \mathrm{m}$ diameter beam spot. Point 1 corresponds to a pure $\mathrm{ZnO}$ rod, point 2 to a hollow rod and point 3 to a rod with higher Ag concentration. 


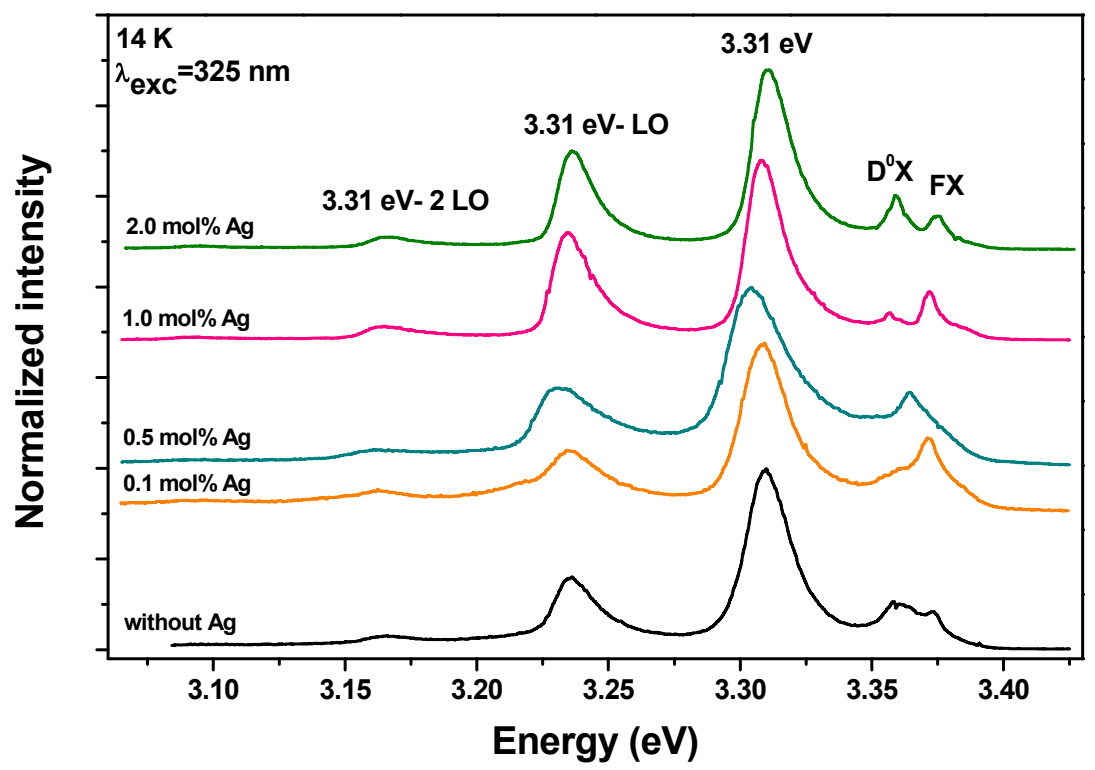

Figure 10 - Low temperature PL spectra of ZnO crystals grown by LAFD with different amounts of silver measured with above band gap excitation $(\mathrm{He}-\mathrm{Cd}, 325 \mathrm{~nm})$.

\subsection{ZnO/CNTs COMPOSITES}

Besides the $\mathrm{ZnO} / \mathrm{Ag}$ hybrid structures, other composites materials have been produced by the flexible LAFD method aiming at their potential applications for solar cells. Two types of $\mathrm{ZnO} / \mathrm{CNTs}$ samples were produced: $\mathrm{ZnO}$ nanostructures deposited on top of VACNTs and a composite in the form of buckypaper. These structures are intended to be incorporated in the dye-sensitized solar cells where the array of VACNTs constitutes the conductive substrate for the semiconductor. Aligned CNTs were selected since they provide more landing sites for the growth of $\mathrm{ZnO}$ nanostructures and the space between each CNT beneficially will disperse the $\mathrm{ZnO}$ nanoparticles compared to disordered CNTs. However, the cell architecture also comprises liquid components such as the dye and the electrolyte, which compromise the alignment of the CNTs ${ }^{62}$. In order to preserve the alignment a complete cover of the CNTs with ZnO particles is needed, which has not yet been accomplished. A detailed characterization of the first type of samples can be found in a previously reported article ${ }^{33}$. Figure 11 shows SEM micrographs of one of those samples. As can be seen, only the nanoparticles are in direct contact with the VACNTs forming a relatively dense coating on the forest surface. In fact, the high density of the CNTs array hinders the ZnO particles penetration into the CNTs forest causing the surface particles distribution. As for the case of the as-grown samples the low temperature PL measurements performed in the ZnO/CNTs composites showed that the emission was dominated by the near band edge recombination although the green band was also observed ${ }^{33}$. Additionally, when a comparison is made with the samples deposited in silicon substrate an enhancement of the overall luminescence intensity was observed for the composites ${ }^{33}$. 

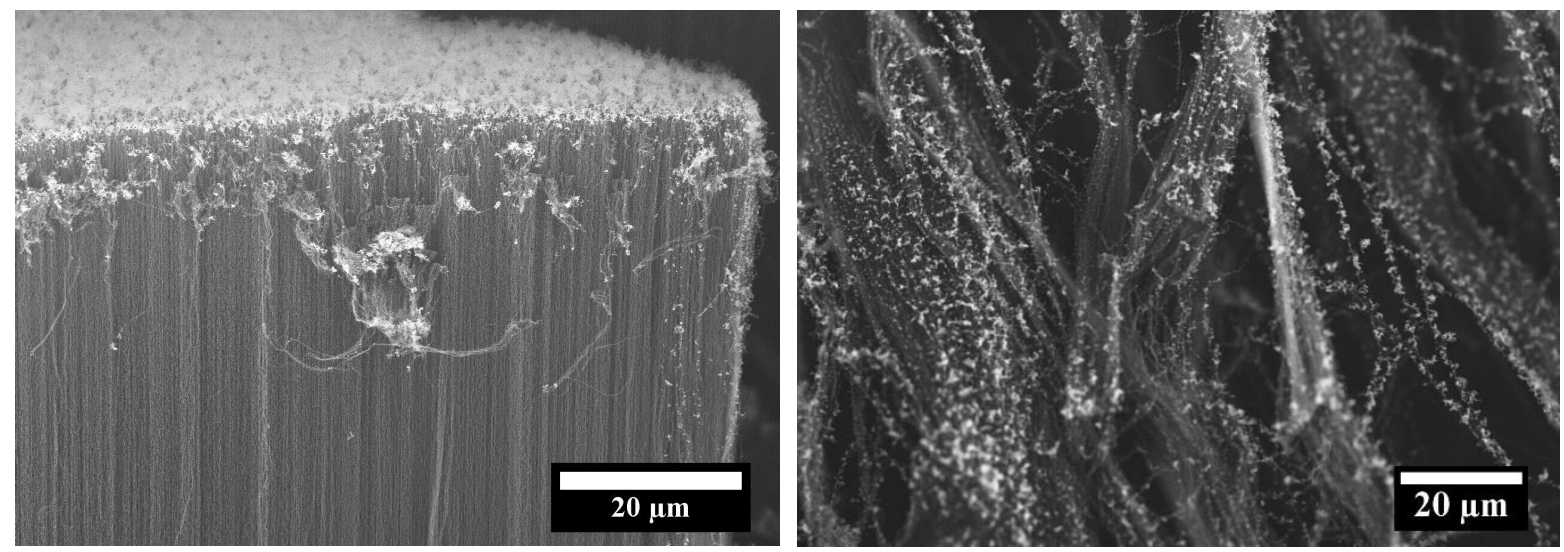

Figure 11 - SEM micrograph of the ZnO nanostructures deposited in VACNTs.

Due to the CNTs alignment loosening during the cell construction, an alternative approach was undertaken using disordered CNTs in the form of buckypapers. Three different types of buckypaper samples were prepared: (a) one containing only CNTs, (b) another with a mixture of $\mathrm{ZnO}$ tetrapods and $\mathrm{COOH}$ functionalized CNTs and (c) another with a mixture of $\mathrm{ZnO}$ nanoparticles and $\mathrm{COOH}$ functionalized CNTs. The SEM micrographs of these samples are shown in Figure 12. The $\mathrm{ZnO}$ tetrapods seem to be widely dispersed in the CNTs while for the case of the particles a small agglomeration can be observed.

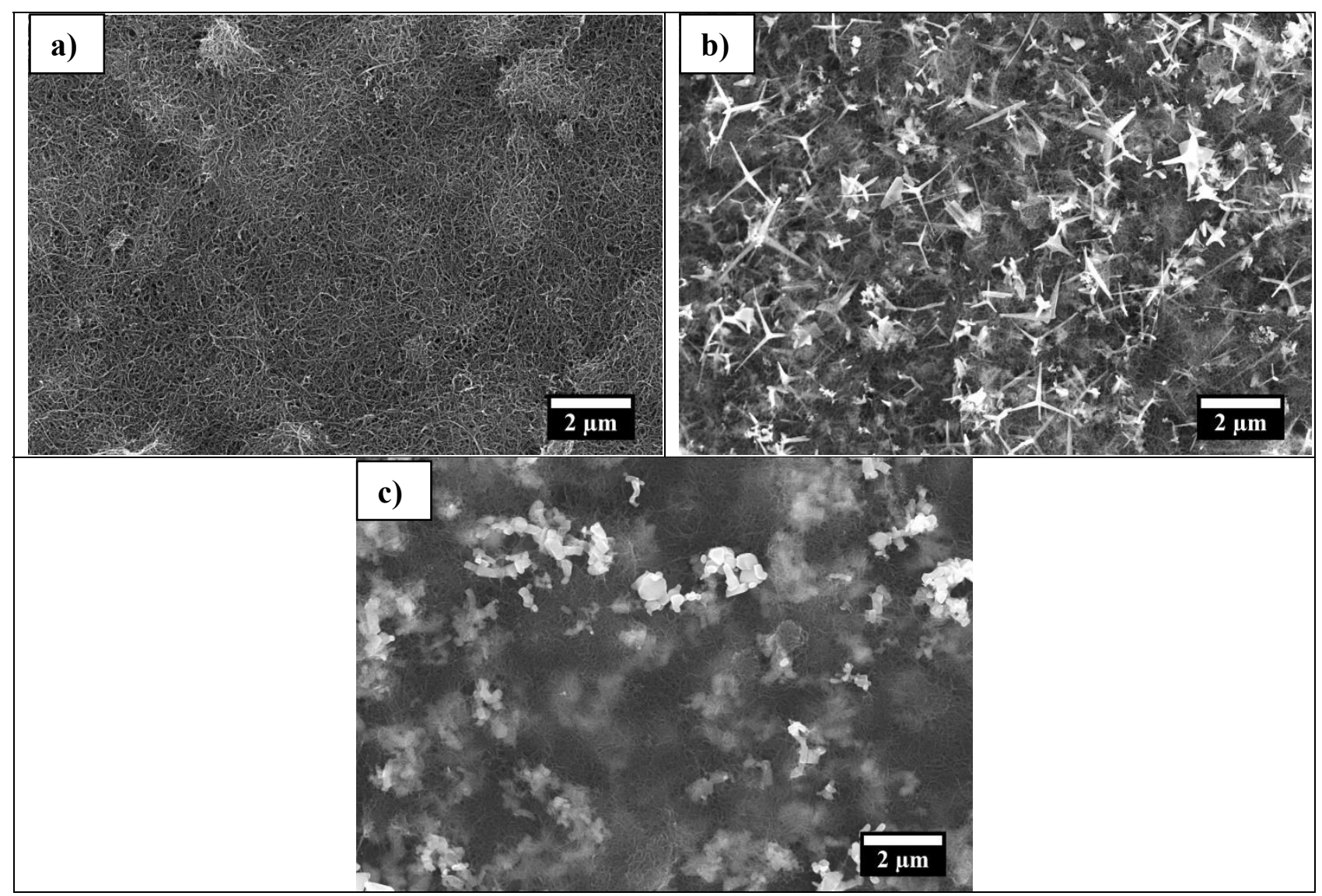

Figure 12 - SEM micrographs of a) CNTs buckypaper, b) CNTs/ZnO tetrapods buckypaper and c) CNTs/ZnO nanoparticles buckypaper. 
Raman measurements using the $632.8 \mathrm{~nm}$ laser line in these CNT/ZnO buckypapers (Figure 13) revealed the expected vibrational modes for the wurtzite structure of $\mathrm{ZnO}$ along with those typically associated with $\mathrm{sp}^{2}$ coordinated carbon $(\mathrm{D}$, $\mathrm{G}$ and $\mathrm{D}^{\prime}$ bands at 1325,1580 and $1610 \mathrm{~cm}^{-1}$, respectively), as previously observed in the VACNTs samples. However, the $\mathrm{D} / \mathrm{G}$ band intensity ratio showed to be higher for the buckypaper material compared to the VACNTs, denoting lower defect density of the later. This is due to the lower quality of the commercial raw materials used to produce the buckypaper.

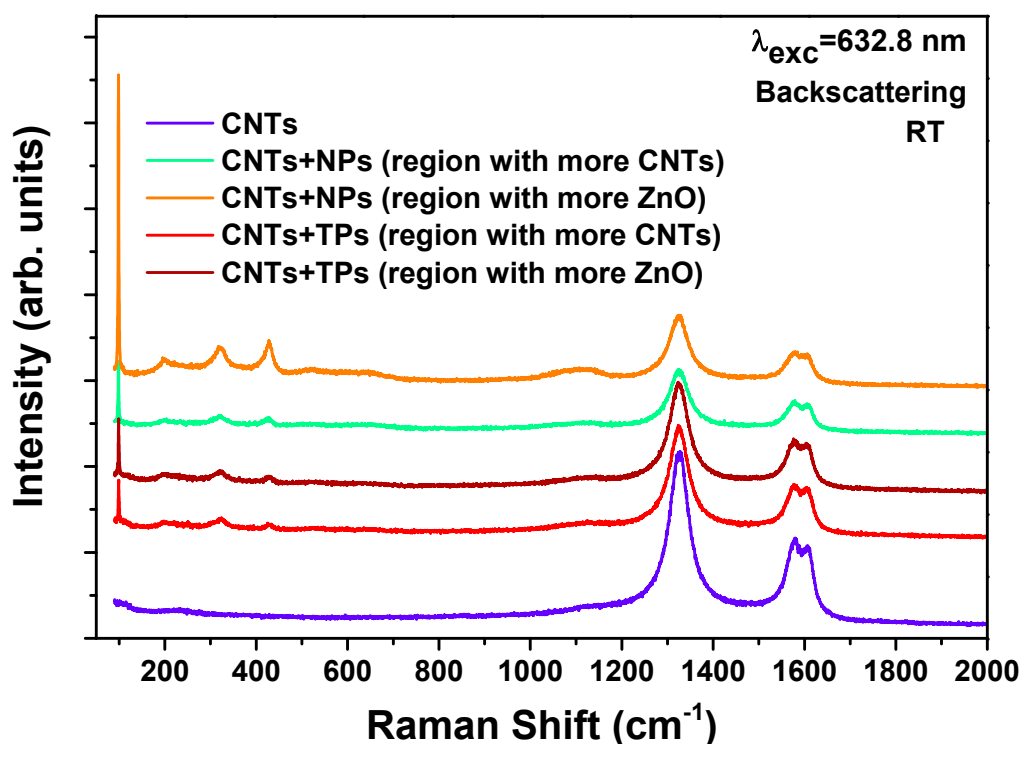

Figure 13 - Raman spectra of the $\mathrm{ZnO} / \mathrm{CNTs}$ composites in form of buckypapers (NP: nanoparticles; TP: tetrapods).

As for the cases of the as-grown and $\mathrm{ZnO} / \mathrm{Ag}$ samples, the $\mathrm{ZnO} / \mathrm{CNTs}$ buckypaper composites were analyzed by low temperature PL (Figure 14) to assess their optical quality. Either by using $\mathrm{ZnO}$ nanoparticles or tetrapods in the composites the luminescence of the $\mathrm{ZnO} / \mathrm{CNTs}$ buckypapers is dominated by a near band edge emission and almost no visible emission is observed. By comparing the PL spectra of the $\mathrm{ZnO}$ nanoparticles and tetrapods before and after their incorporation in the CNTs it should be remarked that the ultraviolet luminescence spectral response reveals an inhomogeneous broadening and the peak position shifts. In the case of the tetrapods a $40 \mathrm{meV}$ low energy shift (from $3.36 \mathrm{eV}$ to $3.32 \mathrm{eV}$ ) is accompanied by a $\sim$ ten times increase of the line full width at half maximum (to $\sim 100 \mathrm{meV}$ ). For the case of the nanoparticles an opposite trend was observed. The main line centered at $3.22 \mathrm{eV}$ exhibits a $\sim 80 \mathrm{meV}$ high energy shift after their incorporation on CNT's buckypaper, accompanied by a small decrease of the FWHM, which is $\sim 100 \mathrm{meV}$. Such behavior has been found in several $\mathrm{ZnO}$ nanostructures grown by distinct methods with distinct morphologies ${ }^{63}-{ }^{65}$. This effect has been explained by distinct surface band bending due to the adsorption of species at the surface of the samples that can bind excitons ${ }^{66}{ }^{69}$, other interactions with surface defects ${ }^{70}{ }^{71}$, distinct coupling strengths of excitons and phonons ${ }^{72},{ }^{73}$ and screening effects ${ }^{74},{ }^{75}$. In that sense, the ultraviolet emission band is likely to be due to the overlap of surface related transitions and $\mathrm{D}^{0} \mathrm{X}$ transitions probing both the surface and sub-surface regions. An additional remark should be accomplished when a comparison between the previously prepared samples with VACNTs ${ }^{33}$ is performed. In this case, only a small enhancement in the overall luminescence was observed without any change in the shape of the emission (Figure 15). This observation, also reported by others ${ }^{76},{ }^{77}$ has been explained on the basis of the increase of the optical centers concentration from where the luminescence is originated due to the high surface to volume ratio ${ }^{77}$, suggesting that for the CNT samples an enhancement of the intrinsic carriers is promoted with above band gap excitation leading to a higher luminescence intensity ${ }^{33}$. On the contrary, the $\mathrm{ZnO} / \mathrm{CNTs}$ buckypapers shown in this work, do not exhibit the usual deep level emission and the ultraviolet band evidences noticed changes before and after embedding the $\mathrm{ZnO}$ structures in the CNTs. 


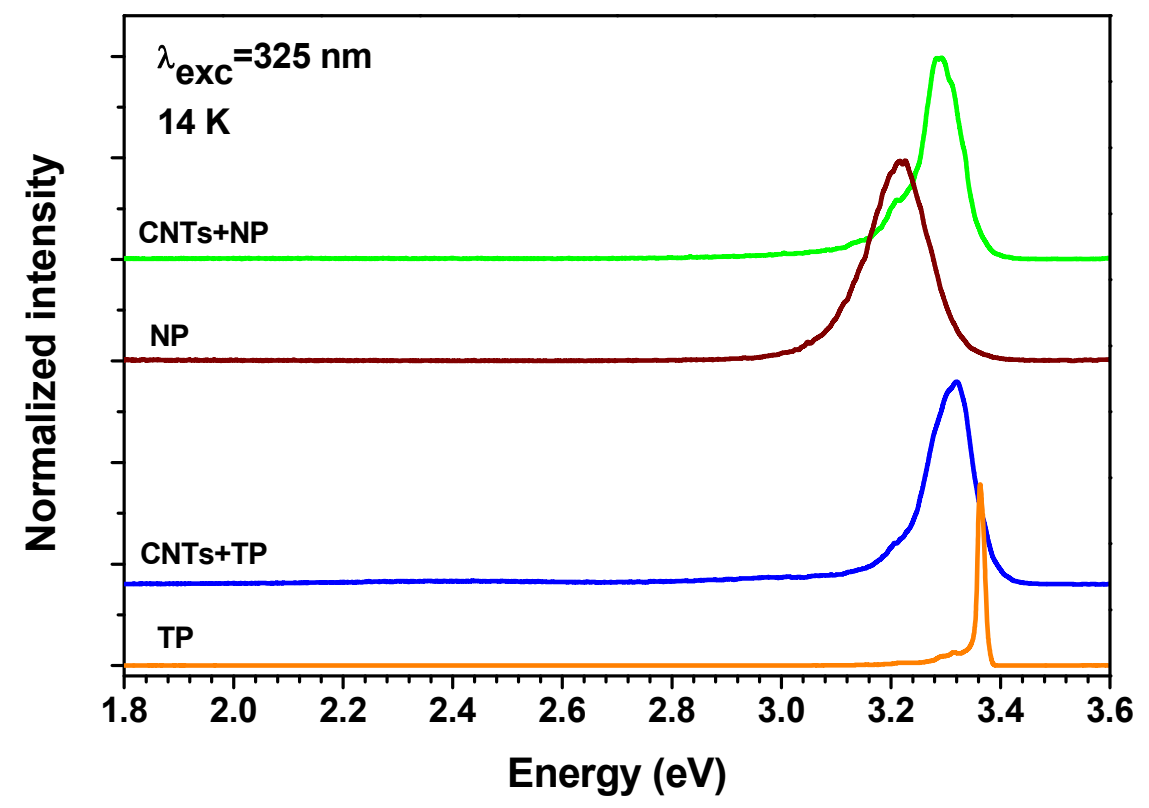

Figure 14 - Low temperature PL spectra of the ZnO/CNTs buckypaper composites.

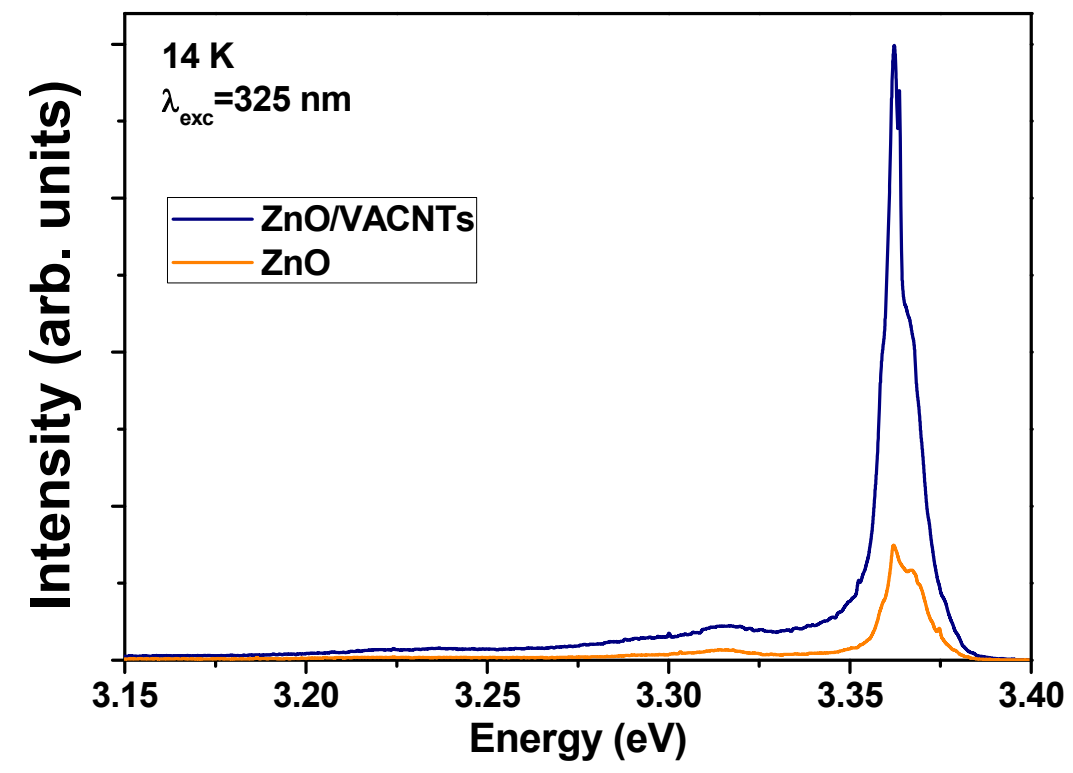

Figure 15 - Comparison between the low temperature PL spectra of the $\mathrm{ZnO}$ and $\mathrm{ZnO} / \mathrm{VACNTs}$ composite. 


\section{CONCLUSIONS}

The LAFD technique was developed as a new method to grow different structures of $\mathrm{ZnO}$ in the absence of catalysts. Different types of morphologies can be produced depending on the thermodynamic and kinetic conditions inside the growth chamber. TEM measurements confirmed the high crystallinity for all the produced structures and the absence of dislocations or stacking faults in the analyzed microrods. Luminescence studies revealed a structured near band edge emission which is an indication of the high optical quality of the $\mathrm{ZnO}$ samples.

For the samples grown in the presence of silver, this metal is mainly present in small particles attached to the surface of the rods. The presence of higher concentration of silver promotes the catalytic growth of $\mathrm{ZnO}$ rods on top of the ones that were grown previously. EDX and PIXE results revealed the inhomogeneous distribution of the silver in the $\mathrm{ZnO}$ crystals. No significant difference was found between the PL features observed for the crystals grown with and without silver.

$\mathrm{ZnO} / \mathrm{CNTs}$ samples were produced in the form of buckypapers and $\mathrm{ZnO}$ nanoparticles deposited on top of arrays of VACNTs. Different features in the Raman and PL spectra were observed for the two sets of samples. In the case of the $\mathrm{ZnO} / \mathrm{VACNTs}$ an enhancement in the overall luminescence was observed when the $\mathrm{ZnO}$ was deposited on top of the CNTs and no change in the shape of the spectra was detected. On the other hand, for the buckypaper samples a change in the shape of the NBE emission was observed when the ZnO was mixed with the CNTs suggesting distinct surface band bending effects when using $\mathrm{ZnO}$ nanoparticles or tetrapods.

\section{ACKNOWLEDGEMENTS}

The authors acknowledge financial support from FCT: PTDC/CTM-NAN/2156/2012, PTDC/FIS-NAN/0973/2012, RECI/FIS-NAN/0183/2012 (FCOMP-01-0124-FEDER-027494), CICYT MAT2010-15206, Pest-C/CTM/LA0025/2011, PEst-C/CTM/LA 25/2013 and PEst-C/CTM/LA0011/2013. J. Rodrigues thanks FCT for her PhD grant, SFRH/ $\mathrm{BD} / 76300 / 2011$. K. Lorenz acknowledges funding by the program FCT Investigador.

\section{REFERENCES}

[1] Look, D.C., "Recent advances in $\mathrm{ZnO}$ materials and devices," Materials Science and Engineering: B 80(1-3), 383-387 (2001).

[2] Lorenz, K., Peres, M., Franco, N., Marques, J.G., Miranda, S.M.C., Magalhães, S., Monteiro, T., Wesch, W., Alves, E., et al., "Radiation damage formation and annealing in $\mathrm{GaN}$ and $\mathrm{ZnO}$," in SPIE OPTO, F. H. Teherani, D. C. Look, and D. J. Rogers, Eds., 79400O-79400O-14 (2011).

[3] Özgür, U., Alivov, Y.I., Liu, C., Teke, A., Reshchikov, M.A., Doğan, S., Avrutin, V., Cho, S.-J., and Morkoç, H., "A comprehensive review of ZnO materials and devices," Journal of Applied Physics 98(4), 041301 (2005).

[4] Jagadish, C., and Pearton, S.J., [Zinc oxide bulk, thin films and nanostructures: processing, properties and applications], Elsevier, 601 (2006).

[5] Huang, M.H., Mao, S., Feick, H., Yan, H., Wu, Y., Kind, H., Weber, E., Russo, R., and Yang, P., “Roomtemperature ultraviolet nanowire nanolasers.," Science (New York, N.Y.) 292(5523), 1897-9 (2001).

[6] Gupta, B., Haranath, D., Chawla, S., Chander, H., Singh, V.N., and Shanker, V., "Self-catalytic synthesis, structure and properties of ultra-fine luminescent $\mathrm{ZnO}$ nanostructures for field emission applications," Nanotechnology 21(22), 225709 (2010). 
[7] Plank, N.O. V., Howard, I., Rao, A., Wilson, M.W.B., Ducati, C., Mane, R.S., Bendall, J.S., Louca, R.R.M., Greenham, N.C., et al., "Efficient ZnO Nanowire Solid-State Dye-Sensitized Solar Cells Using Organic Dyes and Core-shell Nanostructures," The Journal of Physical Chemistry C 113(43), 18515-18522 (2009).

[8] Kaur, M., Bhattacharya, S., Saxena, V., Aswal, D.K., Roy, M., Deshpande, S.K., and Gupta, S.K., "Growth, Characterization and Gas Sensing Properties of Nanotetrapod ZnO," Journal of Nanoscience and Nanotechnology 8(8), 4106-4110 (2008).

[9] Kumar, N., Dorfman, A., and Hahm, J., "Ultrasensitive DNA sequence detection using nanoscale ZnO sensor arrays," Nanotechnology 17(12), 2875 (2006).

[10] Pereira, A.S., Peres, M., Soares, M.J., Alves, E., Neves, A., Monteiro, T., and Trindade, T., "Synthesis, surface modification and optical properties of $\mathrm{Tb}^{3+}$-doped $\mathrm{ZnO}$ nanocrystals," Nanotechnology 17(3), 834-839 (2006).

[11] Chang, P.-C., Fan, Z., Wang, D., Tseng, W.-Y., Chiou, W.-A., Hong, J., and Lu, J.G., “ZnO Nanowires Synthesized by Vapor Trapping CVD Method," Chemistry of Materials 16(24), 5133-5137 (2004).

[12] Peres, M., Soares, M.J., Neves, A.J., Monteiro, T., Sandana, V.E., Teherani, F., and Rogers, D.J., "Morphological and optical studies of self-forming $\mathrm{ZnO}$ nanocolumn and nanocone arrays grown by PLD on various substrates," physica status solidi (b) 247(7), 1695-1698 (2010).

[13] Setiawan, A., Vashaei, Z., Cho, M.W., Yao, T., Kato, H., Sano, M., Miyamoto, K., Yonenaga, I., and Ko, H.J., "Characteristics of dislocations in $\mathrm{ZnO}$ layers grown by plasma-assisted molecular beam epitaxy under different Zn/O flux ratios,” Journal of Applied Physics 96(7), 3763 (2004).

[14] Wang, Z.L., "Nanostructures of zinc oxide,” Materials Today 7(6), 26-33 (2004).

[15] Simon, Q., Barreca, D., Bekermann, D., Gasparotto, A., Maccato, C., Comini, E., Gombac, V., Fornasiero, P., Lebedev, O.I., et al., "Plasma-assisted synthesis of $\mathrm{Ag} / \mathrm{ZnO}$ nanocomposites: First example of photo-induced $\mathrm{H} 2$ production and sensing," International Journal of Hydrogen Energy 36(24), 15527-15537 (2011).

[16] Zheng, Y., Zheng, L., Zhan, Y., Lin, X., Zheng, Q., and Wei, K., “Ag/ZnO Heterostructure Nanocrystals: Synthesis, Characterization, and Photocatalysis,” Inorganic Chemistry 46(17), 6980-6986 (2007).

[17] Georgekutty, R., Seery, M.K., and Pillai, S.C., "A Highly Efficient Ag-ZnO Photocatalyst: Synthesis, Properties, and Mechanism,” The Journal of Physical Chemistry C 112(35), 13563-13570 (2008).

[18] Im, J., Singh, J., Soares, J.W., Steeves, D.M., and Whitten, J.E., "Synthesis and Optical Properties of DithiolLinked ZnO/Gold Nanoparticle Composites," The Journal of Physical Chemistry C 115(21), 10518-10523 (2011).

[19] Lu, W., Liu, G., Gao, S., Xing, S., and Wang, J., "Tyrosine-assisted preparation of Ag/ZnO nanocomposites with enhanced photocatalytic performance and synergistic antibacterial activities.," Nanotechnology 19(44), 445711 (2008).

[20] Karunakaran, C., Rajeswari, V., and Gomathisankar, P., "Antibacterial and photocatalytic activities of sonochemically prepared ZnO and Ag-ZnO," Journal of Alloys and Compounds 508(2), 587-591 (2010).

[21] Zhang, Y., Zhang, Z., Lin, B., Fu, Z., and Xu, J., "Effects of Ag Doping on the Photoluminescence of ZnO Films Grown on Si Substrates," The Journal of Physical Chemistry B 109(41), 19200-19203 (2005). 
[22] Yan, Y., Al-Jassim, M.M., and Wei, S.-H., "Doping of ZnO by group-IB elements," Applied Physics Letters 89(18), 181912 (2006).

[23] Kang, H.S., Ahn, B. Du, Kim, J.H., Kim, G.H., Lim, S.H., Chang, H.W., and Lee, S.Y., "Structural, electrical, and optical properties of p-type ZnO thin films with Ag dopant," Applied Physics Letters 88(20), 202108 (2006).

[24] Wan, Q., Xiong, Z., Dai, J., Rao, J., and Jiang, F., "First-principles study of Ag-based p-type doping difficulty in ZnO,” Optical Materials 30(6), 817-821 (2008).

[25] Sakaguchi, I., and Watanabe, K., "Ion implantation and diffusion behavior of silver in zinc oxide," Journal of the Ceramic Society of Japan 118(1375), 217-219 (2010).

[26] Rodrigues, J., Soares, M.R.N., Carvalho, R.G., Fernandes, A.J.S., Correia, M.R., Monteiro, T., and Costa, F.M., "Synthesis, structural and optical characterization of $\mathrm{ZnO}$ crystals grown in the presence of silver," Thin Solid Films 520(14), 4717-4721 (2012).

[27] Sameera, I., Bhatia, R., and Prasad, V., "Preparation, characterization and electrical conductivity studies of MWCNT/ZnO nanoparticles hybrid," Physica B: Condensed Matter 405(7), 1709-1714 (2010).

[28] Zeng, G.-Y., Nian, K.-S., and Lee, K.-Y., "Characteristics of a dye-sensitized solar cell based on an anode combining $\mathrm{ZnO}$ nanostructures with vertically aligned carbon nanotubes," Diamond and Related Materials 19(12), 1457-1460 (2010).

[29] Ok, J.G., Tawfick, S.H., Juggernauth, K.A., Sun, K., Zhang, Y., and Hart, A.J., “Electrically Addressable Hybrid Architectures of Zinc Oxide Nanowires Grown on Aligned Carbon Nanotubes," Advanced Functional Materials 20(15), 2470-2480 (2010).

[30] Li, F., Cho, S.H., Son, D.I., Kim, T.W., Lee, S.-K., Cho, Y.-H., and Jin, S., "UV photovoltaic cells based on conjugated $\mathrm{ZnO}$ quantum dot/multiwalled carbon nanotube heterostructures," Applied Physics Letters 94(11), 111906 (2009).

[31] Craciun, V., Guilloux-Viry, M., Alexe, M., Catalán Bernabé, G., Fanciulli, M., Ouldhamadouche, N., Achour, A., Musa, I., Ait Aissa, K., et al., "Structural and photoluminescence characterization of vertically aligned multiwalled carbon nanotubes coated with $\mathrm{ZnO}$ by magnetron sputtering," Thin Solid Films 520(14), 4816-4819 (2012).

[32] Lin, Y.-H., Lee, P.-S., Hsueh, Y.-C., Pan, K.-Y., Kei, C.-C., Chan, M.-H., Wu, J.-M., Perng, T.-P., and Shih, H.C., "Atomic Layer Deposition of Zinc Oxide on Multiwalled Carbon Nanotubes for UV Photodetector Applications," Journal of The Electrochemical Society 158(2), K24-K27 (2011).

[33] Rodrigues, J., Mata, D., Fernandes, A.J.S., Neto, M.A., Silva, R.F., Monteiro, T., and Costa, F.M., “ZnO nanostructures grown on vertically aligned carbon nanotubes by laser-assisted flow deposition," Acta Materialia 60(13-14), 5143-5150 (2012).

[34] Takahashi, K., Yoshikawa, A., and Sandhu, A., [Wide Bandgap Semiconductors: Fundamental Properties and Modern Photonic and Electronic devices], Springer (2007).

[35] Rodrigues, J., Peres, M., Soares, M.R.N., Fernandes, A.J.S., Ferreira, N., Ferro, M., Neves, A.J., Monteiro, T., and Costa, F.M., "ZnO Nano/Microstructures Grown by Laser Assisted Flow Deposition," Journal of Nano Research 18-19, 129-137 (2012). 
[36] Mata, D., Silva, R.M., Fernandes, A.J.S., Oliveira, F.J., Costa, P.M.F.J., and Silva, R.F., "Upscaling potential of the CVD stacking growth method to produce dimensionally-controlled and catalyst-free multi-walled carbon nanotubes," Carbon 50(10), 3585-3606 (2012).

[37] Mata, D., Oliveira, F.J., Ferro, M., Gomes, P.S., Fernandes, M.H., Lopes, M.A., and Silva, R.F., "Multifunctional Carbon Nanotube/Bioceramics Modulate the Directional Growth and Activity of Osteoblastic Cells," Journal of Biomedical Nanotechnology 10(5), 725-743 (2014).

[38] Moschini, G., Valkovic, V., and Grime, G.W., "The ' Q factor' method: quantitative microPIXE analysis using RBS normalisation," Nuclear Instruments and Methods in Physics Research Section B: Beam Interactions with Materials and Atoms 109, 170-174 (1996).

[39] Ronning, C., Shang, N.G., Gerhards, I., Hofsäss, H., and Seibt, M., "Nucleation mechanism of the seed of tetrapod ZnO nanostructures," Journal of Applied Physics 98(3), 034307 (2005).

[40] Meyer, B.K., Alves, H., Hofmann, D.M., Kriegseis, W., Forster, D., Bertram, F., Christen, J., Hoffmann, A., Straßburg, M., et al., "Bound exciton and donor-acceptor pair recombinations in $\mathrm{ZnO}$," physica status solidi (b) 241(2), 231-260 (2004).

[41] Teke, A., Özgür, Ü., Doğan, S., Gu, X., Morkoç, H., Nemeth, B., Nause, J., and Everitt, H., "Excitonic fine structure and recombination dynamics in single-crystalline ZnO," Physical Review B 70(19), 195207 (2004).

[42] Lischka, K., Waag, A., Mariette, H., Neugebauer, J., Wagner, M.R., Kunert, H.W., Machatine, A.G.J., Hoffmann, A., Niyongabo, P., et al., "Bound and free excitons in ZnO. Optical selection rules in the absence and presence of time reversal symmetry," Microelectronics Journal 40(2), 289-292 (2009).

[43] Dingle, R., "Luminescent Transitions Associated With Divalent Copper Impurities and the Green Emission from Semiconducting Zinc Oxide,” Physical Review Letters 23(11), 579-581 (1969).

[44] Byrne, D., Herklotz, F., Henry, M.O., and McGlynn, E., "Unambiguous identification of the role of a single Cu atom in the $\mathrm{ZnO}$ structured green band.," Journal of physics. Condensed matter : an Institute of Physics journal 24(21), $215802(2012)$.

[45] Reynolds, D., Litton, C., and Collins, T., "Zeeman Effects in the Edge Emission and Absorption of ZnO," Physical Review 140(5A), A1726-A1734 (1965).

[46] Klingshirn, C., Lévy, R., Grun, J.B., and Hönerlage, B., "Scattering processes involving bound excitons in highly excited ZnO," Solid State Communications 20(4), 413-417 (1976).

[47] Thonke, K., Gruber, T., Teofilov, N., Schönfelder, R., Waag, A., and Sauer, R., "Donor-acceptor pair transitions in ZnO substrate material," Physica B: Condensed Matter 308, 945-948 (2001).

[48] Look, D.C., Reynolds, D.C., Litton, C.W., Jones, R.L., Eason, D.B., and Cantwell, G., "Characterization of homoepitaxial p-type ZnO grown by molecular beam epitaxy,” Applied Physics Letters 81(10), 1830 (2002).

[49] Schirra, M., Schneider, R., Reiser, A., Prinz, G.M., Feneberg, M., Biskupek, J., Kaiser, U., Krill, C.E., Thonke, K., et al., "Stacking fault related 3.31-eV luminescence at 130-meV acceptors in zinc oxide," Physical Review B $77(12), 125215$ (2008).

[50] Özgür, U., Hofstetter, D., and Morkoç, H., "ZnO Devices and Applications: A Review of Current Status and Future Prospects," Proceedings of the IEEE 98(7), 1255-1268 (2010). 
[51] Brandt, M., von Wenckstern, H., Benndorf, G., Lange, M., Dietrich, C.P., Kranert, C., Sturm, C., SchmidtGrund, R., Hochmuth, H., et al., "Identification of a donor-related recombination channel in $\mathrm{ZnO}$ thin films," Physical Review B 81(7), 073306 (2010).

[52] Wang, L., and Giles, N.C., "Temperature dependence of the free-exciton transition energy in zinc oxide by photoluminescence excitation spectroscopy,” Journal of Applied Physics 94(2), 973 (2003).

[53] Wischmeier, L., Voss, T., Rückmann, I., Gutowski, J., Mofor, A., Bakin, A., and Waag, A., "Dynamics of surface-excitonic emission in ZnO nanowires,” Physical Review B 74(19), 195333 (2006).

[54] Grabowska, J., Meaney, A., Nanda, K., Mosnier, J.-P., Henry, M., Duclère, J.-R., and McGlynn, E., "Surface excitonic emission and quenching effects in $\mathrm{ZnO}$ nanowire/nanowall systems: Limiting effects on device potential,” Physical Review B 71(11), 115439 (2005).

[55] Schirra, M., Schneider, R., Reiser, A., Prinz, G.M., Feneberg, M., Biskupek, J., Kaiser, U., Krill, C.E., Sauer, R., et al., "Acceptor-related luminescence at $3.314 \mathrm{eV}$ in zinc oxide confined to crystallographic line defects," Physica B: Condensed Matter 401-402, 362-365 (2007).

[56] Thonke, K., Schirra, M., Schneider, R., Reiser, A., Prinz, G.M., Feneberg, M., Biskupek, J., Kaiser, U., and Sauer, R., "The role of stacking faults and their associated $0.13 \mathrm{ev}$ acceptor state in doped and undoped $\mathrm{ZnO}$ layers and nanostructures," Microelectronics Journal 40(2), 210-214 (2009).

[57] Tainoff, D., Masenelli, B., Melinon, P., Belsky, A., Ledoux, G., Amans, D., Dujardin, C., Fedorov, N., and Martin, P., "Probing the excitonic emission of ZnO nanoparticles using UV-VUV excitations," Journal of Luminescence 129(12), 1798-1801 (2009).

[58] Qiu, H., Meyer, B., Wang, Y., and Wöll, C., "Ionization Energies of Shallow Donor States in ZnO Created by Reversible Formation and Depletion of H Interstitials," Physical Review Letters 101(23), 236401 (2008).

[59] Bock, F.X., Christensen, T.M., Rivers, S.B., Doucette, L.D., and Lad, R.J., "Growth and structure of silver and silver oxide thin films on sapphire," Thin Solid Films 468(1-2), 57-64 (2004).

[60] Cuscó, R., Alarcón-Lladó, E., Ibáñez, J., Artús, L., Jiménez, J., Wang, B., and Callahan, M., “Temperature dependence of Raman scattering in ZnO," Physical Review B 75(16), 165202 (2007).

[61] Siegle, H., Kaczmarczyk, G., Filippidis, L., Litvinchuk, A.P., Hoffmann, A., and Thomsen, C., "Zone-boundary phonons in hexagonal and cubic GaN," Physical Review B 55(11), 7000-7004 (1997).

[62] Robertson, J., Kawarada, H., Kohn, E., Sitar, Z., Wirth, C.T., and Hofmann, S., "Surface properties of vertically aligned carbon nanotube arrays," Diamond and Related Materials 17(7), 1518-1524 (2008).

[63] Wang, Z.L., "Zinc oxide nanostructures: growth, properties and applications," Journal of Physics: Condensed Matter 16(25), R829-R858 (2004).

[64] Djurišić, A.B., Leung, Y.H., Tam, K.H., Hsu, Y.F., Ding, L., Ge, W.K., Zhong, Y.C., Wong, K.S., Chan, W.K., et al., "Defect emissions in $\mathrm{ZnO}$ nanostructures," Nanotechnology 18(9), 095702 (2007).

[65] Djurisić, A.B., and Leung, Y.H., "Optical properties of ZnO nanostructures.," Small (Weinheim an der Bergstrasse, Germany) 2(8-9), 944-61 (2006). 
[66] Biswas, M., Jung, Y.S., Kim, H.K., Kumar, K., Hughes, G.J., Newcomb, S., Henry, M.O., and McGlynn, E., "Microscopic origins of the surface exciton photoluminescence peak in ZnO nanostructures," Physical Review B 83(23), 235320 (2011).

[67] Richters, J.-P., Voss, T., Wischmeier, L., Rückmann, I., and Gutowski, J., "Influence of polymer coating on the low-temperature photoluminescence properties of ZnO nanowires," Applied Physics Letters 92(1), 011103 (2008).

[68] Yang, Y., Tay, B.K., Sun, X.W., Sze, J.Y., Han, Z.J., Wang, J.X., Zhang, X.H., Li, Y.B., and Zhang, S., "Quenching of surface-exciton emission from $\mathrm{ZnO}$ nanocombs by plasma immersion ion implantation," Applied Physics Letters 91(7), 071921 (2007).

[69] Zhang, Y.Z., He, H.P., Jin, Y.Z., Zhao, B.H., Ye, Z.Z., and Tang, H.P., "Reduced bound exciton and surface exciton emissions in Al-doped $\mathrm{ZnO}$ nanorods exposed to ambient air," Journal of Applied Physics 104(10), 103529 (2008).

[70] Fallert, J., Hauschild, R., Stelzl, F., Urban, A., Wissinger, M., Zhou, H., Klingshirn, C., and Kalt, H., “Surfacestate related luminescence in ZnO nanocrystals," Journal of Applied Physics 101(7), 073506 (2007).

[71] Shi, W.S., Agyeman, O., and Xu, C.N., "Enhancement of the light emissions from zinc oxide films by controlling the post-treatment ambient," Journal of Applied Physics 91(9), 5640 (2002).

[72] Voss, T., Bekeny, C., Wischmeier, L., Gafsi, H., Börner, S., Schade, W., Mofor, A.C., Bakin, A., and Waag, A., "Influence of exciton-phonon coupling on the energy position of the near-band-edge photoluminescence of $\mathrm{ZnO}$ nanowires," Applied Physics Letters 89(18), 182107 (2006).

[73] Ahn, C.H., Mohanta, S.K., Lee, N.E., and Cho, H.K., "Enhanced exciton-phonon interactions in photoluminescence of ZnO nanopencils," Applied Physics Letters 94(26), 261904 (2009).

[74] Studenikin, S.., Cocivera, M., Kellner, W., and Pascher, H., "Band-edge photoluminescence in polycrystalline $\mathrm{ZnO}$ films at 1.7K," Journal of Luminescence 91(3), 223-232 (2000).

[75] Reynolds, D.C., Look, D.C., and Jogai, B., "Combined effects of screening and band gap renormalization on the energy of optical transitions in ZnO and GaN," Journal of Applied Physics 88(10), 5760 (2000).

[76] Wen, H.-C., Hung, C.-I., Tsai, H.-J., Lu, C.-K., Lai, Y.-C., and Hsu, W.-K., "ZnO-coated carbon nanotubes: an enhanced and red-shifted emission band at UV-VIS wavelength," Journal of Materials Chemistry 22(27), 13747 (2012).

[77] Gupta, B.K., Grover, V., Gupta, G., and Shanker, V., "Highly efficient luminescence from hybrid structures of $\mathrm{ZnO} /$ multi-walled carbon nanotubes for high performance display applications," Nanotechnology 21(47), 475701 (2010). 